\title{
Strategic assessment of COVID-19 pandemic in Bangladesh: comparative lockdown scenario analysis, public perception, and management for sustainability
}

\author{
Mashura Shammi, et al. [full author details at the end of the article]
}

Received: 1 May 2020 / Accepted: 7 July 2020 / Published online: 18 July 2020

(c) Springer Nature B.V. 2020

\begin{abstract}
Community transmission of COVID-19 is happening in Bangladesh-the country which did not have a noteworthy health policy and legislative structures to combat a pandemic like COVID-19. Early strategic planning and groundwork for evolving and established challenges are crucial to assemble resources and react in an appropriate timely manner. This article, therefore, focuses on the public perception of comparative lockdown scenario analysis and how they may affect the sustainable development goals (SDGs) and the strategic management regime of COVID-19 pandemic in Bangladesh socio-economically as well as the implications of the withdrawal of partial lockdown plan. Scenario-based public perceptions were collected via a purposive sampling survey method through a questionnaire. Datasets were analysed through a set of statistical techniques including classical test theory, principal component analysis, hierarchical cluster analysis, Pearson's correlation matrix and linear regression analysis. There were good associations among the lockdown scenarios and response strategies to be formulated. Scenario 1 describes how the death and infection rate will increase if the Bangladesh Government withdraws the existing partial lockdown. Scenario 2 outlines that limited people's movement will enable low-level community transmission of COVID-19 with the infection and death rate will increase slowly $(r=0.540, p<0.01)$. Moreover, there will be less supply of necessities of daily use with a price hike $(r=0.680, p<0.01)$. In scenario 3 , full lockdown will reduce community transmission and death from COVID-19 $(r=0.545, p<0.01)$. However, along with the other problems gender discrimination and gender-based violence will increase rapidly $(r=0.661$, $p<0.01)$. Due to full lockdown, the formal and informal business, economy, and education sector will be hampered severely $(R=0.695)$. Subsequently, there was a strong association between the loss of livelihood and the unemployment rate which will increase due to business shutdown $(p<0.01)$. This will lead to the severe sufferings of poor and vulnerable communities in both urban and rural areas $(p<0.01)$. All these will further aggravate the humanitarian needs of the most vulnerable groups in the country in the coming months to be followed which will undoubtedly affect the Bangladesh targets to achieve the SDGs of 2030 and other development plans that need to be adjusted. From our analysis, it was apparent that maintaining partial lockdown with business and economic activities with social distancing and public health guidelines is the best strategy to maintain. However, as
\end{abstract}

Electronic supplementary material The online version of this article (https://doi.org/10.1007/s1066 $8-020-00867-y)$ contains supplementary material, which is available to authorized users. 
the government withdrew the partial lockdown, inclusive and transparent risk communication towards the public should be followed. Recovery and strengthening of the health sector, economy, industry, agriculture, and food security should be focused on under the "new normal standard of life" following health guidelines and social distancing. Proper response plans and strategic management are necessary for the sustainability of the nation.

\section{Graphic abstract}

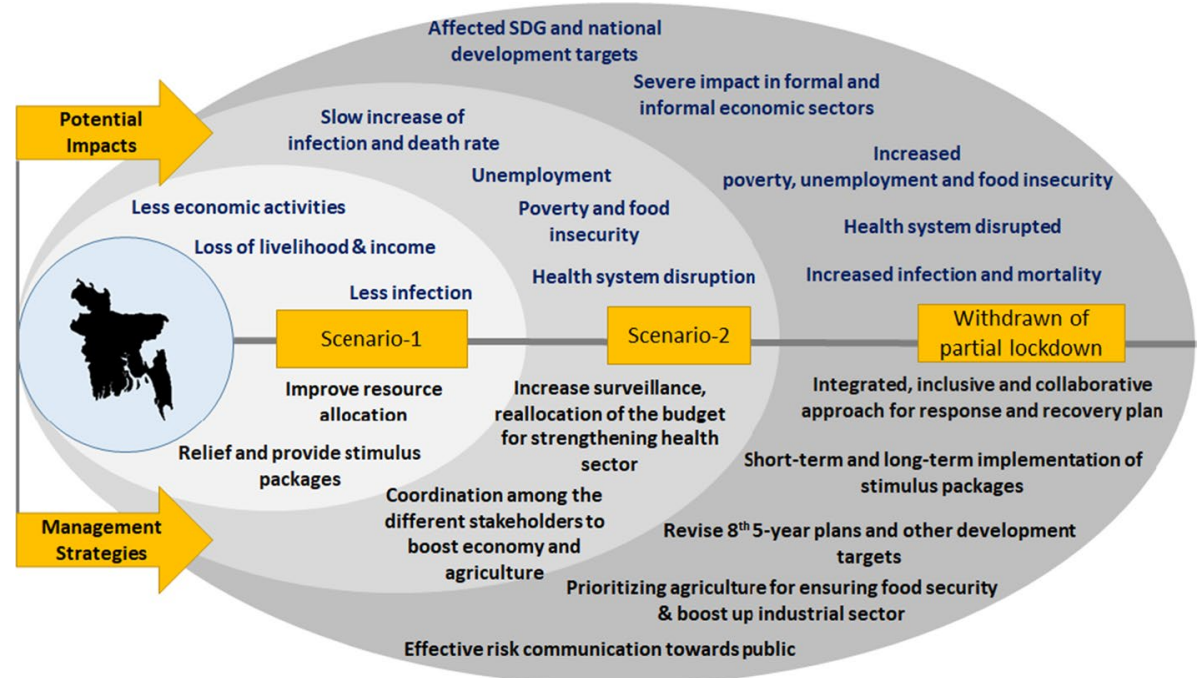

Keywords COVID-19 pandemic $\cdot$ Impact $\cdot$ Lockdown $\cdot$ Strategic management $\cdot$ Scenario analysis $\cdot$ Response plans

\begin{tabular}{ll}
\multicolumn{2}{l}{ Abbreviations } \\
COVID-19 & Coronavirus disease of 2019 \\
CA & Cluster analysis \\
CTT & Classical test theory \\
GOB & Government of Bangladesh \\
ICU & Intensive care unit \\
LRA & Linear regression analysis \\
PCA & Principal component analysis \\
PCM & Pearson's correlation matrix \\
PPE & Personal protective equipment \\
SDG & Sustainable development goals \\
WHO & World Health Organization
\end{tabular}

\section{Introduction}

According to the WHO, globally as of 31 May 2020, there have been 6,218,927 confirmed cases of COVID-19, including 372,344 deaths (WHO 2020a). Despite its rapid transmission rate (Gautam and Trivedi 2020) national emergency response plans, public 
health efforts and public guidelines have slowed its development and reduced the scale of COVID-19 outbreak, preventing hundreds of thousands of cases within 50 days in China, South Korea, Taiwan, Vietnam, New Zealand and elsewhere (Business Insider 2020; Tian et al. 2020; Zhang et al. 2020). Strengths (S), weaknesses (W), opportunities $(\mathrm{O})$, and threats (T) (SWOT) analysis method identifies a strategic basis and assesses a relevant and relative approach to prevent and control the COVID-19 pandemic (Wang and Wang 2020). The use of evidence-based strategic emergency control measures in the epidemic areas and the integration of resources from multiple systems, including business, community, technology, education, and transportation, across China was successful in the containment (Liu et al. 2020). Earlier in May, WHO (2020b) outlined a guideline fort the governments that want to lift lockdown or restriction, containing six criteria: (1) infection transmission is under control; (2) health system can "detect, test, isolate, treat every infection case and track every case"; (3) risks are minimized for the vulnerable hot spot areas, such as nursing homes; (4) protective measures are established for educational institutes, workplaces, and other essential places; (5) the probable risk of imported new cases can be managed; and (6) the communities are thoroughly educated, engaged, empowered, and willing to function according to the new standard or normal. There should be a strategic analysis to lift the lockdown or shutdown. Lifting the lockdown too early or too quickly can raise the rate of the infection, while maintaining the six steps does not guarantee reemergence of the COVID-19 infections.

The public healthcare system and unique legislative structures focus on current preparedness, and other key capacities allow and encourage preparedness and response to the pandemic (Oppenheim et al. 2020). Rather than the highly centralized approach, an integration of decentralized approaches is required to slow down the pandemic (Carinci 2020). Yet the logistical challenges associated with the healthcare supplies and mobilizing the medical forces and rapid construction of new medical facilities intervened crucially to prevent a pandemic, providing frontline healthcare workers' safety, and reducing the mortality ( $\mathrm{Ji}$ et al. 2020). Bangladesh did not have a noteworthy health sectoral policy and legislative structures to combat COVID-19 like a pandemic. On 5 March 2020, "National Preparedness and Response Plan for COVID-19, Bangladesh" was released to facilitate planning and identify response levels and risk assessment (IEDCR/ DGHS/GOB 2020). There are only 399 Intensive Care Units (ICUs) in the government hospitals in Bangladesh-of which 218 are in the Dhaka city alone. Although $20 \%$ of COVID-19 patients require ICU, due to its shortage of it the hospitals are unable to provide it (TBS News 2020a).

Bangladesh confirmed the first coronavirus case on 8 March 2020. In response to the COVID-19 pandemic, the Government of Bangladesh (GoB) declared special "general leave" from 26 March in the name of "lockdown" and extended it up to 30 May 2020 in seven different time slots. Both the words "general leave" and "lockdown" created confusion among the most socio-economically vulnerable groups in the country. The so-called lockdown and the social distancing strategy in a densely populated country of more than 165 million did not work. After the 45 days of a lockdown or partial lockdown, Italy, Brazil, Spain and Bangladesh had shown more than 100 deaths from COVID-19 infection (Table 1). Currently, Bangladesh is going through widespread community transmission (Figs. 1, 2), while the lockdown was withdrawn on 30 May 2020. As of 31 May 2020, after the 65 days of lockdown, Dhaka was normal as usual where no social distancing or any health guideline was maintained. The number of confirmed patients stands at 47,153 , with 650 deaths. Figure 3 shows the daily percentage of new cases per total test per day. Until now with the presence of 52 laboratories in the country, the total number of tests 


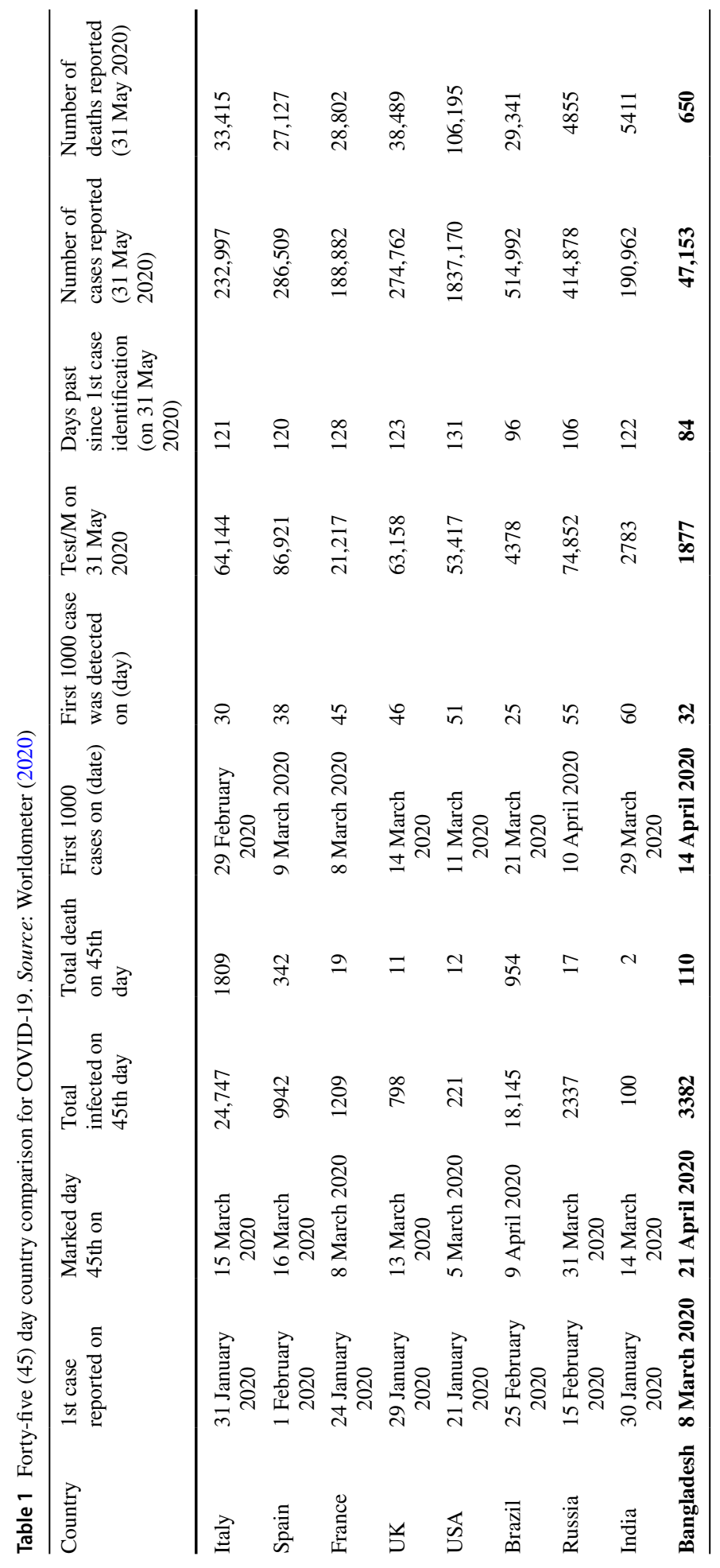




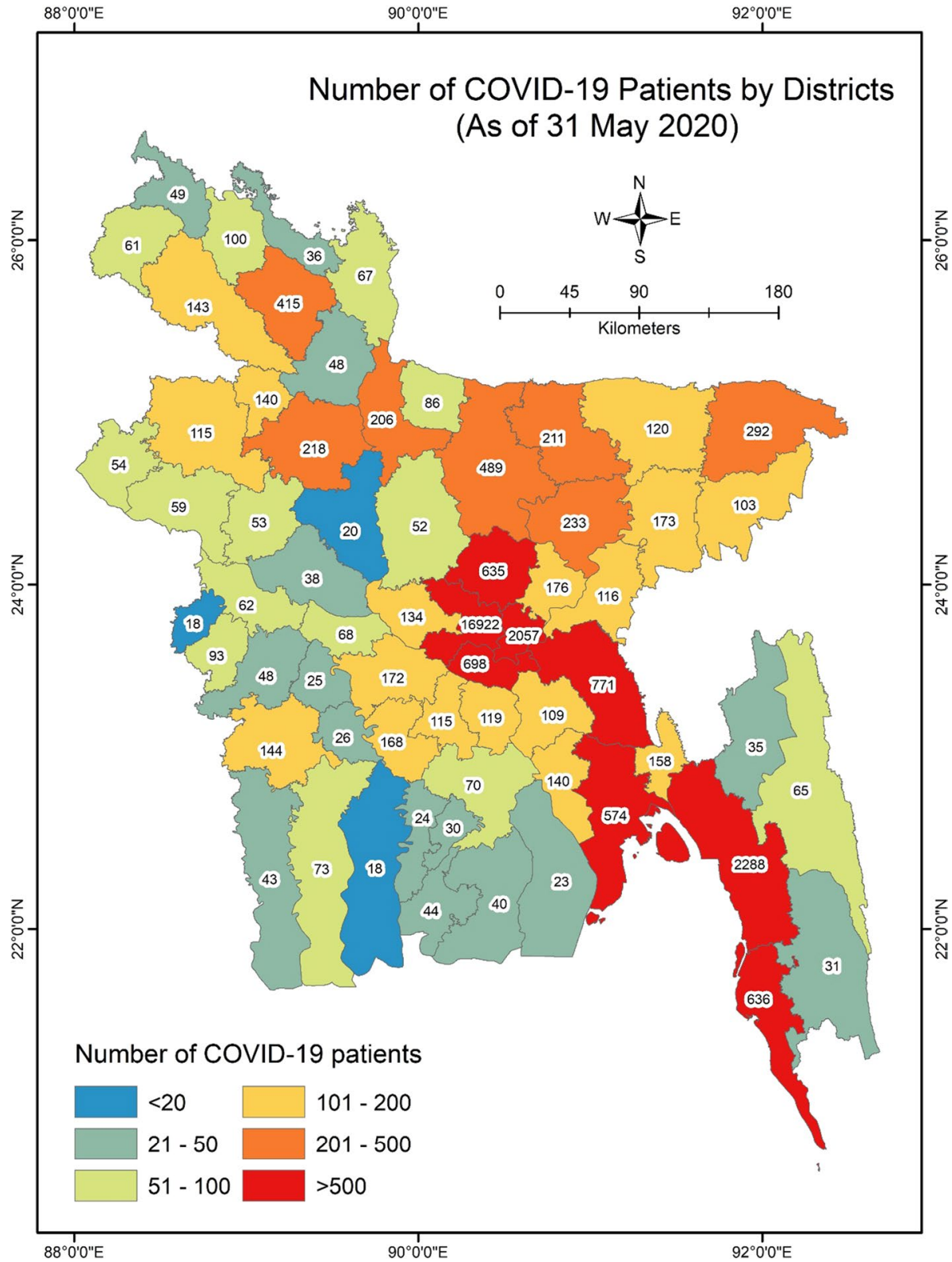

Fig. 1 Map of the study area showing the number of COVID-19 confirmed patient. Data source: IEDCR (2020)

performed is 308,940 which is 1877 tests/1 million (IECDR 2020; Worldometer 2020). The number is one of the lowest in the world (Table 1).

It is predictable that during a pandemic, a humanitarian crisis may arise in a developing country like Bangladesh. In most incidents, it will be the combined effects of a variety of shortages that will likely culminate in the worst outcomes (Truog et al. 


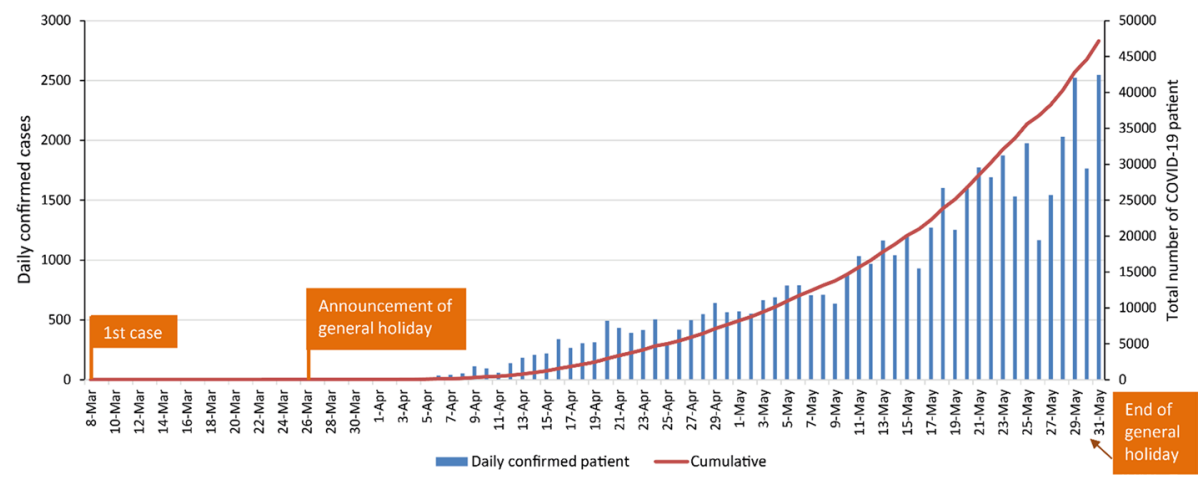

Fig. 2 Daily confirmed COVID-19 patient count

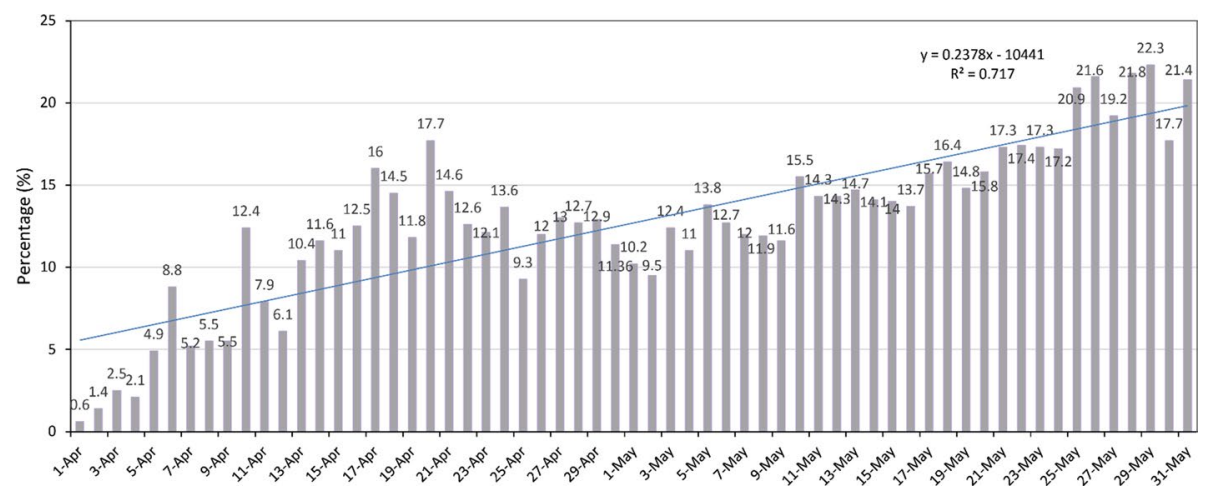

Fig. 3 Percentage of new cases per total test per day

2020). This can lead to a shortage of basic needs including foods, goods, and services such as job loss, economic and financial loss, food insecurity, famine, social conflicts, and deaths. Besides, an impact on the psychosocial and socio-economic and health and well-being of the citizens may be affected which we had shown in our previous study (Shammi et al. 2020). While predicting all the subsequent impact of the COVID-19 pandemic is challenging, early strategic planning and groundwork for the evolving and established challenges will be crucial to assemble resources and react in an appropriate timely manner. Moreover, as the GoB has lifted the lockdown without flattening the curve of the pandemic what should be the socio-economic management strategy for the government at this stage. This article, therefore, focuses on the public perception of comparative lockdown scenario analysis and the strategic management regime of COVID-19 pandemic in Bangladesh. As there is no such prediction on how long the situation prevails, the absence/lack of management strategy for an epidemiological and socio-economic emergency response might be a tool to assess the forthcoming situation under a set of specific scenarios. Therefore, the objective of this study is to analyse long-term strategic management of the pandemic in three different lengths of scenarios in a resource-limited setting of the so-called lockdown of the country. The outcome can play a crucial role to formulate emergency response strategy to tackle the COVID-19 
pandemic both epidemiologically and socio-economically in developing countries like Bangladesh.

\section{Methodology}

\subsection{Study procedure}

Considering the impact of current socio-economic lockdown for flattening the curve of COVID-19 infection in Bangladesh, this study identifies three scenarios of lockdown based on literature review, the lockdown situation in Bangladesh, and the global lockdown practices in different countries. A total of 54 statements were used to develop the questionnaire to understand the scenario-based impact assessment and management of COVID-19 outbreak in Bangladesh. We had taken expert suggestions, consultations, and cross-validation of 54 statements for getting perceptions from a different group of people. We have used Google Form to prepare the questionnaire and conduct the survey online. An online database of target Bangladeshi participants was prepared by reviewing different online social platforms of different expert groups in Bangladesh, considering their current activities, responsibilities, and engagement related to COVID-19 response in socio-economic sectors, planning, and policymaking. The prepared questionnaire with an introductory paragraph outlining the objective of the study was then shared through email, Facebook, Messenger, LinkedIn, and WhatsApp with selective and relevant people considering the purposive sampling method. The questionnaire survey was conducted from 09 April to 11 April 2020. A five-point (1-5) scenario-based Likert scale was employed to test whether each respondent understands the statements described ranging from strongly disagree to strongly agree.

\subsection{Research sample and population}

The target population was general Bangladeshi citizens age 18 years and older. The inclusion of the respondents was different social groups like university faculty and scholars, government officials, non-government officials, development workers or practitioners, doctors, engineers and technologists, youth leaders and students, businessmen and industry officials, banking and finance corporates, researchers, and others. The answers to the survey questionnaires were the voluntary basis. A total of 159 responses were recorded during the survey.

According to the survey findings, the ratio of male to female participants was 3 $(n=113): 1 \quad(n=46)$. The composition of age groups was $44 \%$ (18-25 years old), $41 \%$ (26-35 years old), and 15\% (36-55 years old), respectively. However, the average age of the respondents $(n=159)$ was 28.44 years $(S D \pm 6.51) .40 \%$ of the youth leader was mostly students as they are the dynamic group in the society, also involved in COVID-19 response, volunteer social works, job seeking, research and reporting activities. Rest of the $60 \%$ participants belonged to various professions of doctors, civil service officials, development practitioners, non-government officials, expert panels, and university scholars.

\subsection{Data analysis}

The descriptive statistics (e.g. frequencies, percentages, and Student $T$ test) were used to understand the participant's characteristics. Applying the Statistical Package for the Social 
Science (SPSS) v. 25.0, datasets were analysed via a set of statistical tools such as principal component analysis (PCA), hierarchical cluster analysis (HCA), Pearson's correlation coefficient (PCC), multiple regression analysis (MRA), and classical test theory (CTT) analysis. PCA is one of the population data reduction techniques that indicate each potentiality of variables and their significance level in a huge sample size. Before conducting the PCA, Kaiser-Maier-Olkin (KMO) and Bartlett's sphericity tests were applied to confirm the necessity of this analysis. The results of the KMO $>0.5$ (the KMO value was 0.8 in this research) and the significance of Bartlett's sphericity test at $p<0.01$ verified our datasets to be fitted for the PCA (Islam et al. 2020). The number of factors chosen was based on the Kaiser's normalization principle, where the only factors with eigenvalues $>1.0$ were regarded. From CTT analysis, Cronbach's alpha was employed to test the consistency and reliability of the factor loadings in this study. Cronbach's alpha validation values ranged from 0.925 to 0.934 (the Cronbach's alpha reliability value was 0.925 indicating that these statements are appropriate in social science study (Table 2) (DeVellis 1991). The hierarchical cluster analysis (HCA) is a crucial means of identifying relationships among all socioenvironmental variables. The HCA assists to classify a population into different groups based on the similar characteristics of a set of the dataset that may show causes, effects, and or the source of any undetected socio-environmental crisis. Furthermore, hierarchical clustering was adopted to determine the possible number of clusters. The one-way ANOVA test was conducted to confirm the significant differences in the variance at $p<0.05$.

\subsection{Ethics}

Participants were informed of the specific purpose of the study. Participants' consent was taken before the survey and they remained anonymous. The survey was completed only once, and the survey could be completed/terminated whenever they wished. The survey content and procedure were reviewed and approved by the Department of Public Health and Informatics, Jahangirnagar University.

\section{Results and discussions}

\subsection{Setting the scenarios}

Reductions of COVID-19 pandemic have been linked with the cessation of public transport, educational institutions, the closing of entertainment and business centres, and the prohibition of public meetings. Averagely, cities that carried out control measures of lockdown within the first week of the outbreak reported fewer cases compared to the cities which started control later (Tian et al. 2020). Vietnam, the communist country bordering

Table 2 Cronbach's alpha value

\begin{tabular}{llll}
\hline Scenario & Number of items & Reliability & Validity \\
\hline LS1 & 18 & 0.881 & 0.897 \\
LS2 & 18 & 0.853 & 0.865 \\
LS3 & 18 & 0.873 & 0.89 \\
Total & 54 & 0.925 & 0.934 \\
\hline
\end{tabular}


China with a population of 95 million, has been an under-reported low-cost success story of the pandemic, which has had just 268 coronavirus cases and no deaths due to strong public health systems, good governance and transparent communication, strict quarantine approach, and contact tracing. From the first-known international cases on 23 January 2020, Vietnam quarantined anyone who arrived from the high-risk area and closed its porous 1400-km border with China to all but essential trade and travel. In February, it quarantined more than 10,000 people in the Son Loi village due to infections. It also closed all schools, colleges, universities, and all other educational institutions beginning in February. On March 22, the Vietnamese government suspended all foreign entries (WEF 2020a). It also decided early on to impose a 14-day quarantine on anyone arriving in Vietnam from a high-risk area. On April 22, Vietnam eased its lockdown effort. Unfortunately, in the European region such as worst-affected Italy, France, and UK, the region in the Americas such as the USA and now Brazil experienced most deaths due to the failure to understand the disease and keep continuing their activities such as travelling and tourism which spiked the death rates, or delayed lockdown efforts (Table 3). The case of New Zealand is interesting in the sense that it pursued an eradication tactic historically based on a mitigation model and focused on slower arrival of the virus, followed by a range of measures to flatten the curve of cases and deaths (Cousins 2020). The measures include increased testing, screening, strict quarantine of the infected person, contact tracing, and surveillance. The same measures have been adopted by South Korea, Taiwan, and many successful countries.

Luo (2020), of Singapore University of Technology and Design (http://www.sutd.edu. sg) forecasted using a data-driven model that by 30 May 2020, 99\% of the infection case will end, while $100 \%$ will end by 15 July 2020 for Bangladesh. However, the forecast does not seem to be valid considering the present context in Bangladesh. At this background, a scenario-based assessment under different assumptive situation considering the socio-economic and cultural attitude of the country could better identify the impacts. The later section of the article mainly focused on the different scenario and their possible management and their way forwards.

In our study, we have considered global lockdown practice, country situation analysis, and expert suggestions to set three scenarios for impact analysis and possible management strategies which are:

Lockdown scenario 1: Withdraw the existing partial lockdown (LS1)

Lockdown scenario 2: Continue the existing partial lockdown (LS2)

Lockdown scenario 3: Full lockdown/shutdown with an exit plan (LS3)

A total of 54 scenario-based statements were set, and perception-based statistical analysis was performed. The descriptive statistics are presented in Table 4, which exhibits the percentage, mean, and standard deviation (SD), describing the responses of participants to the related scenarios for all 54 statements from each of the 159 respondents and the direction of each statement in the studied survey datasets. Sect. 3.2-3.4 discusses the impacts of different lockdown scenarios.

\subsection{Impact analysis of lockdown scenario 1}

Considering the withdrawal of existing partial lockdown, the results of CTT analysis and the corrected inter-item correlation analysis reveal that eight statements have low corrected item-total correlation values $(<0.30)$. This includes, people will start moving towards 


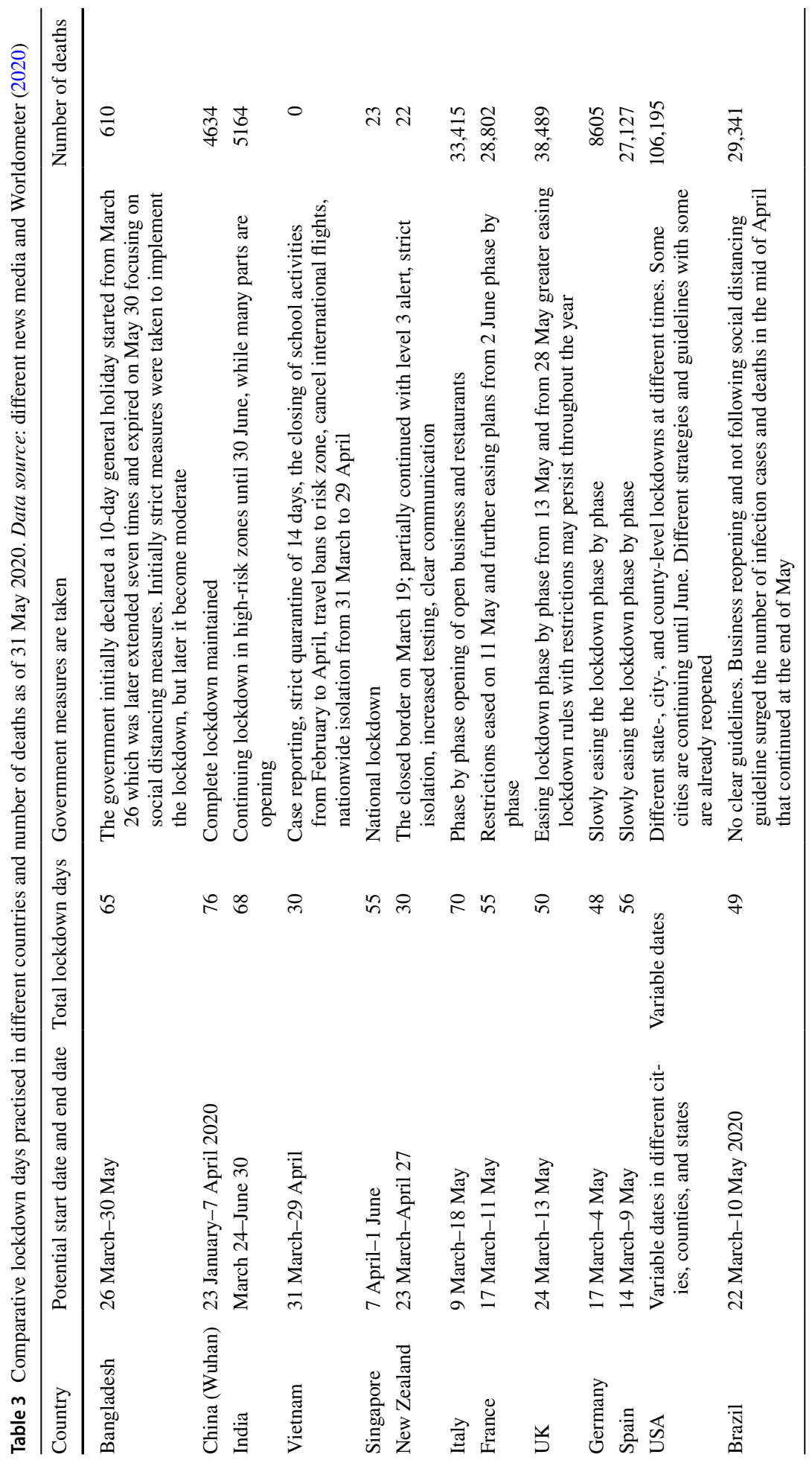




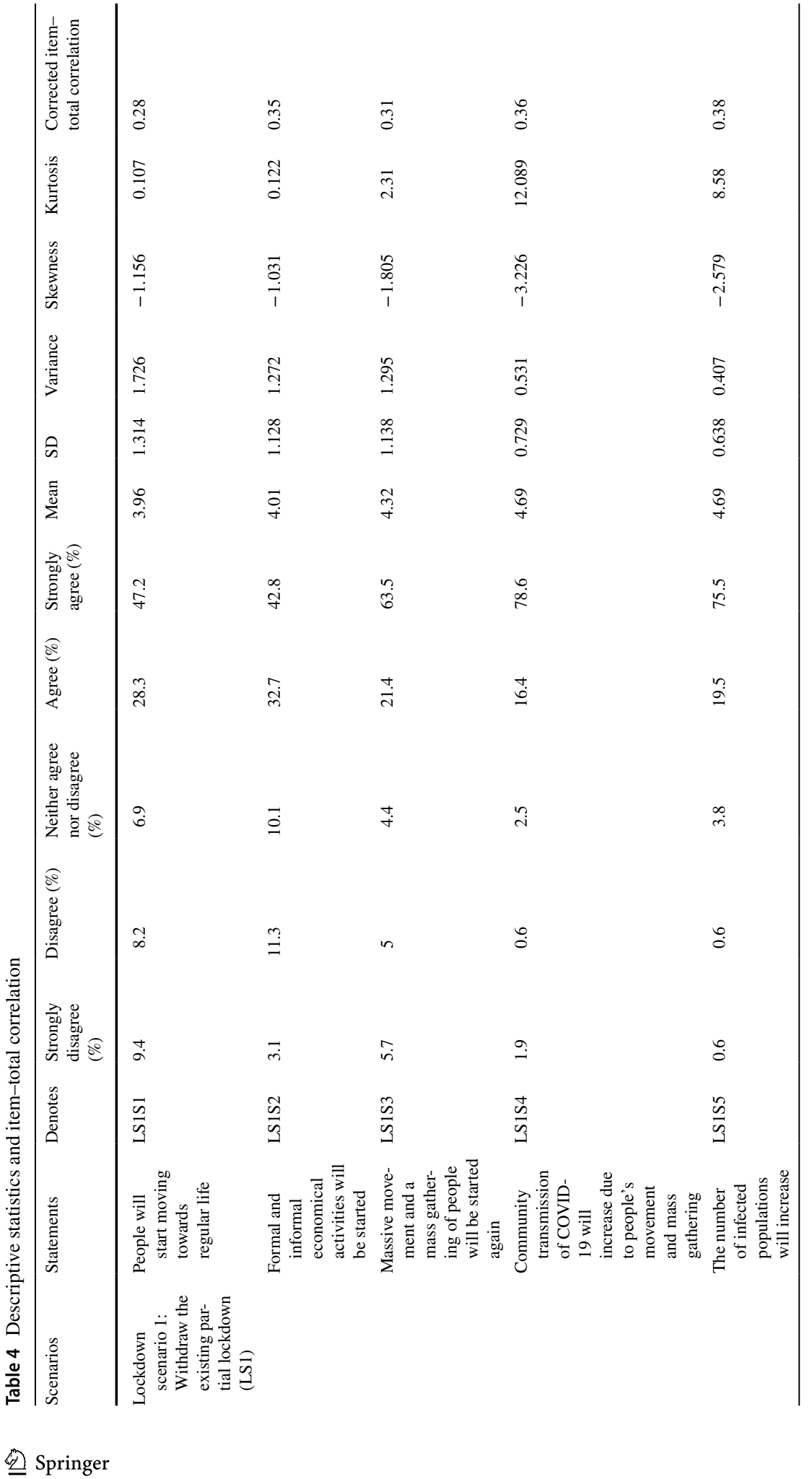




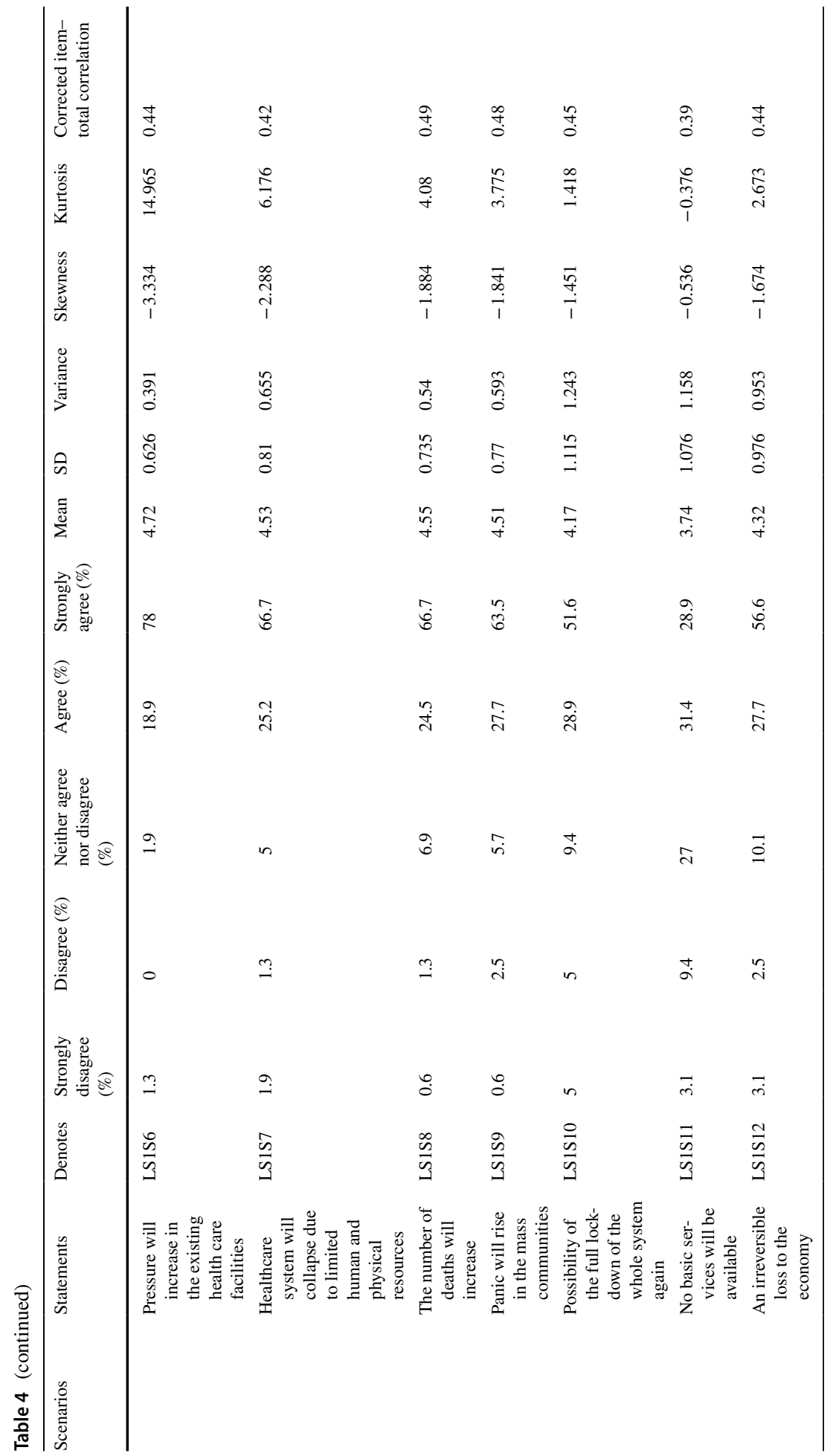




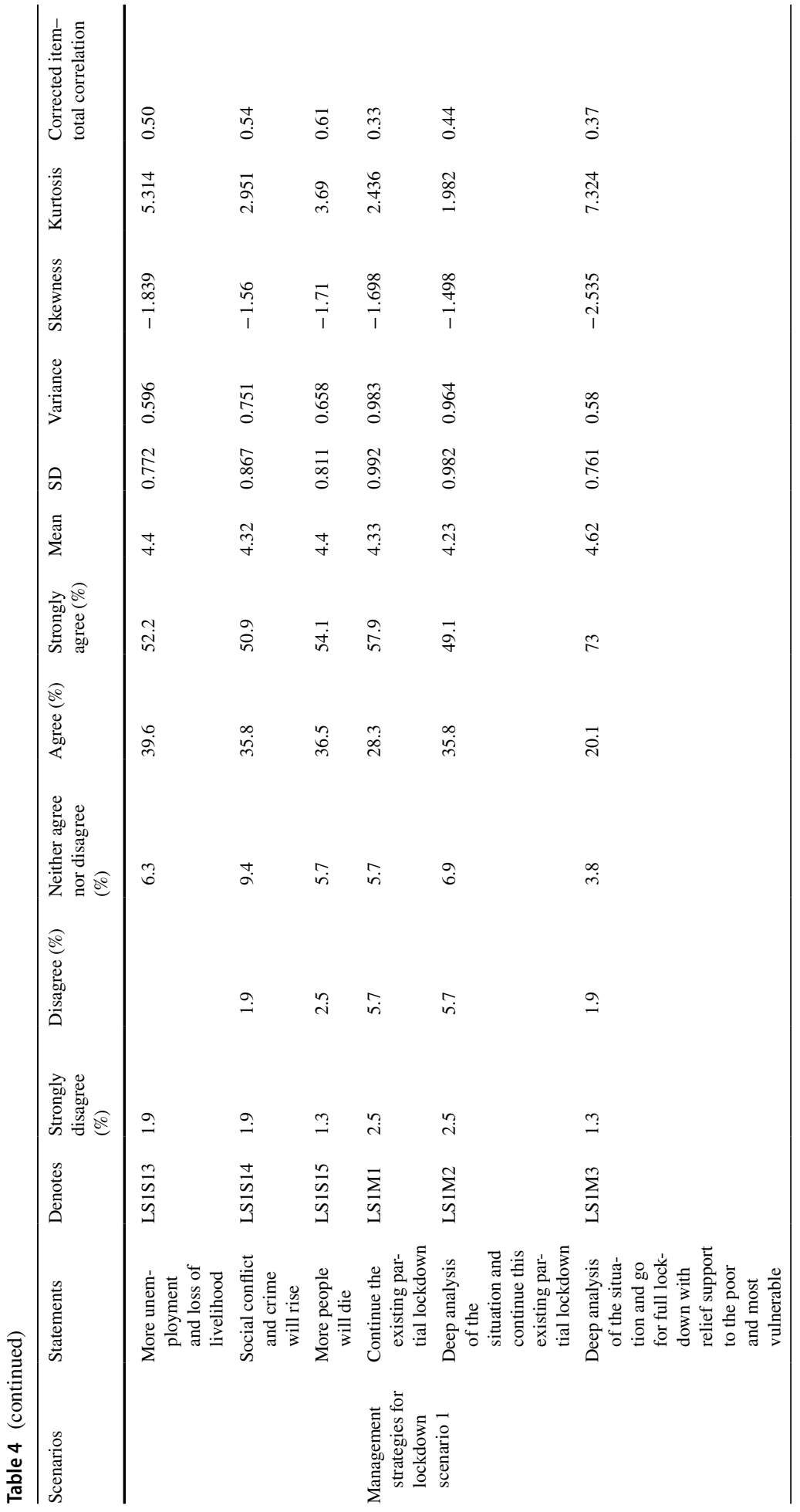




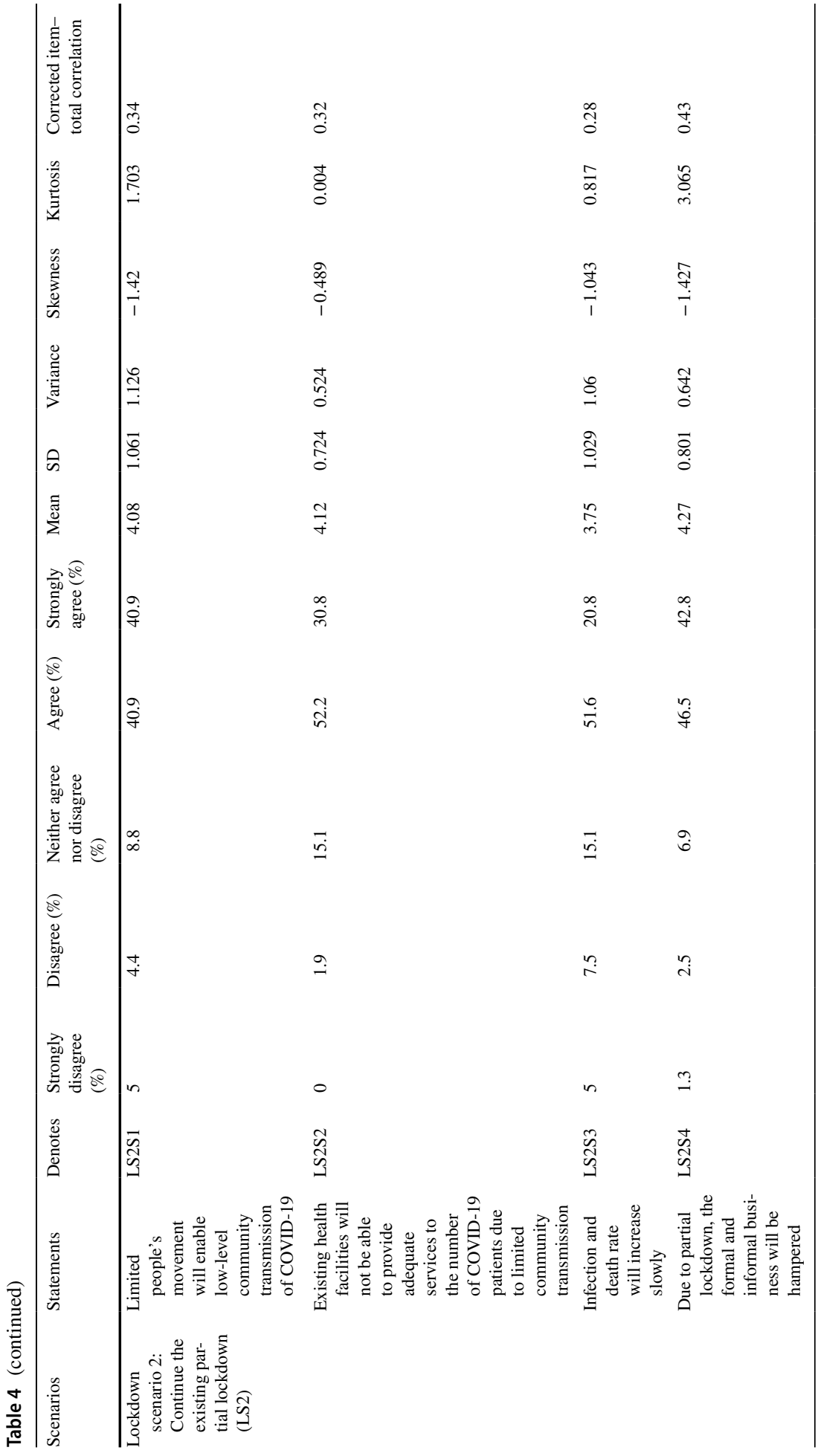




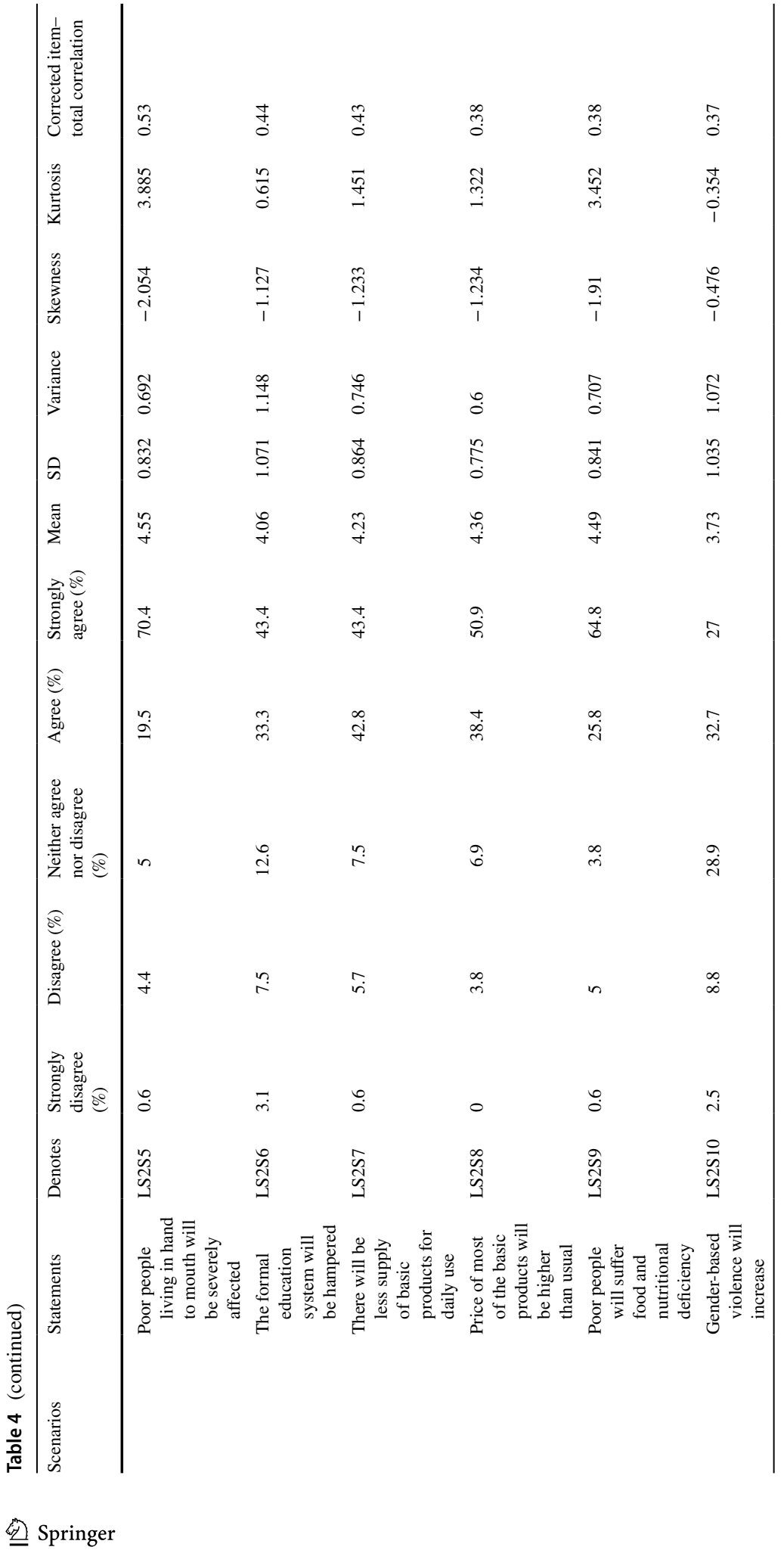




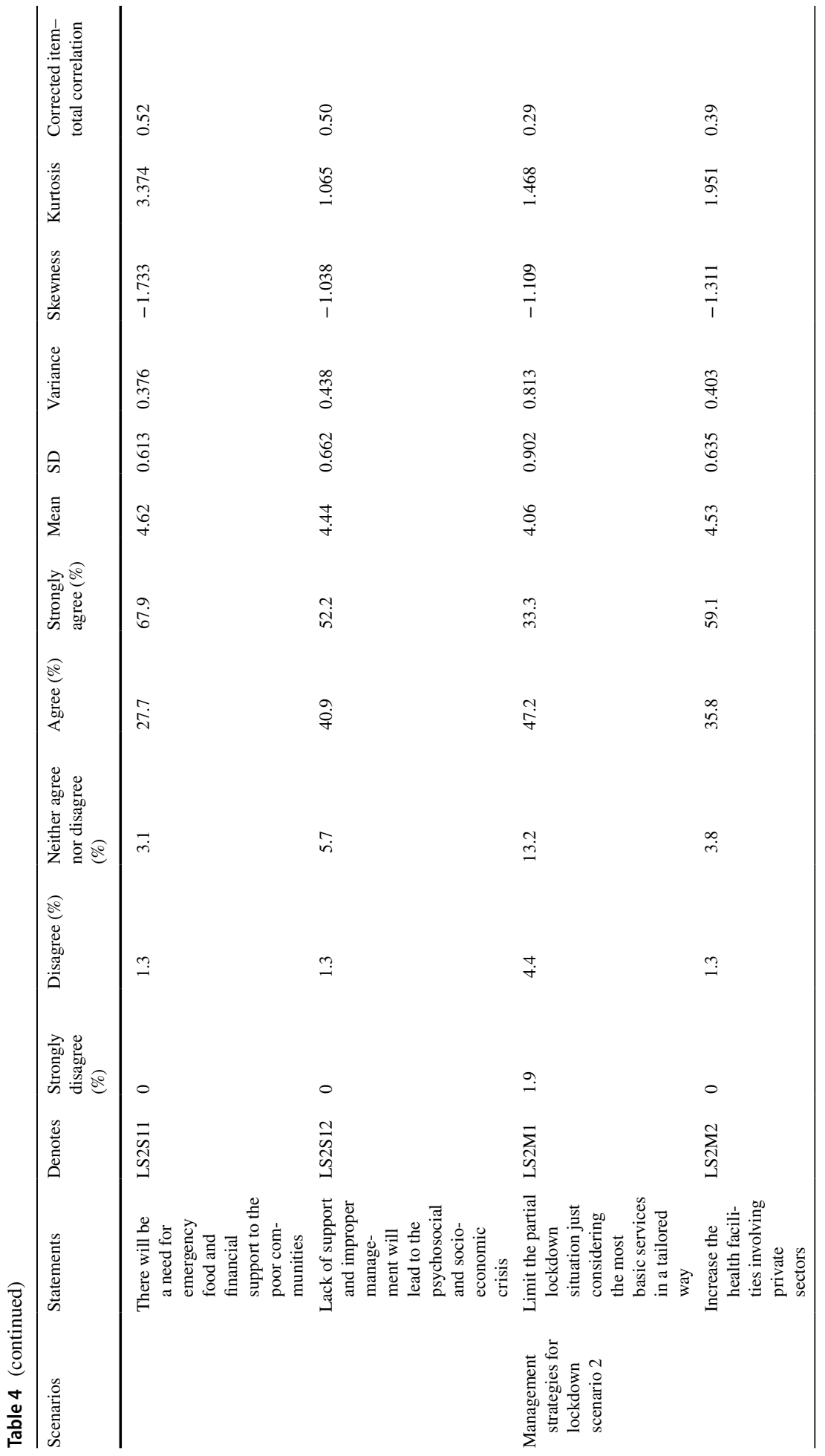




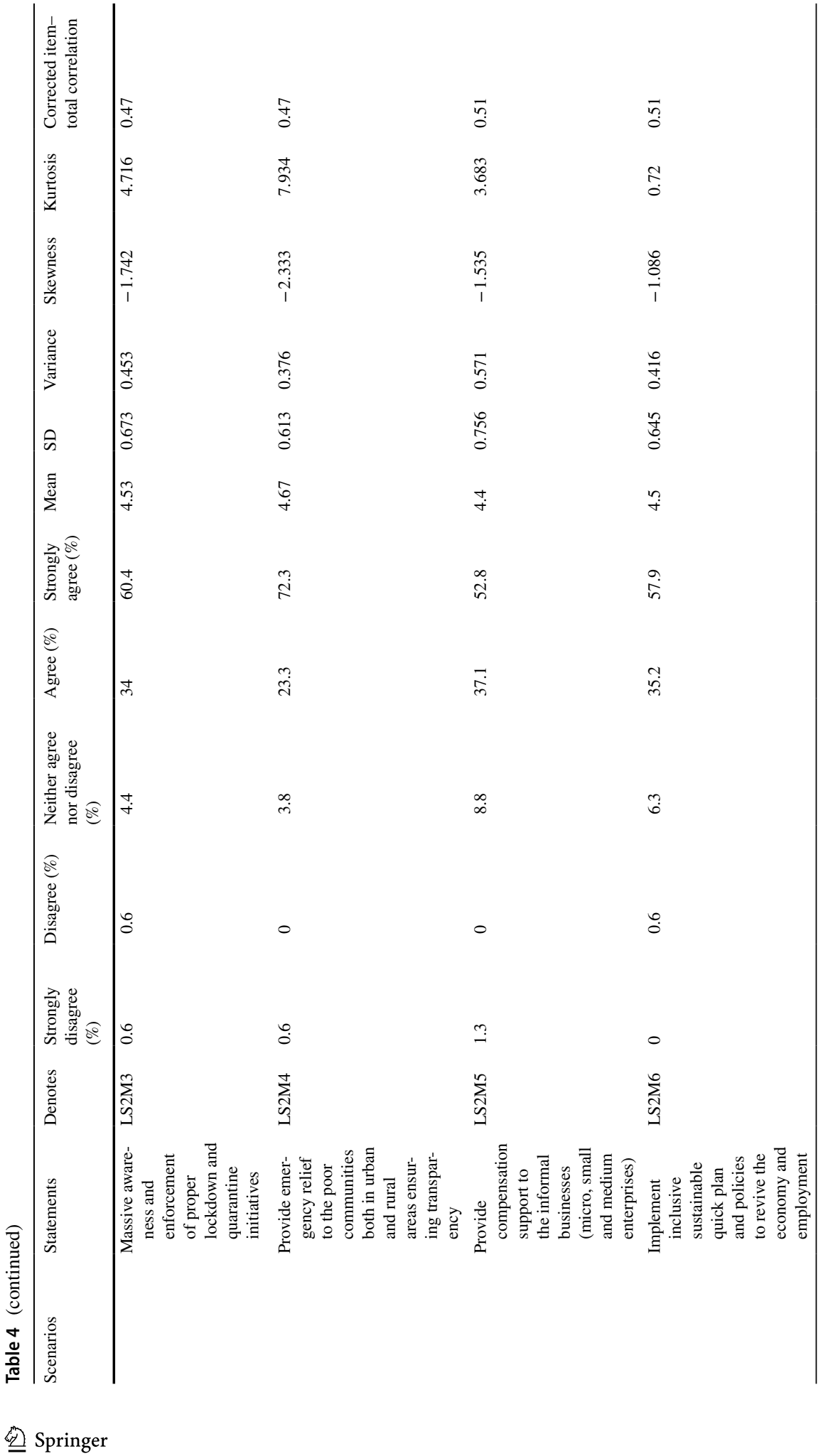




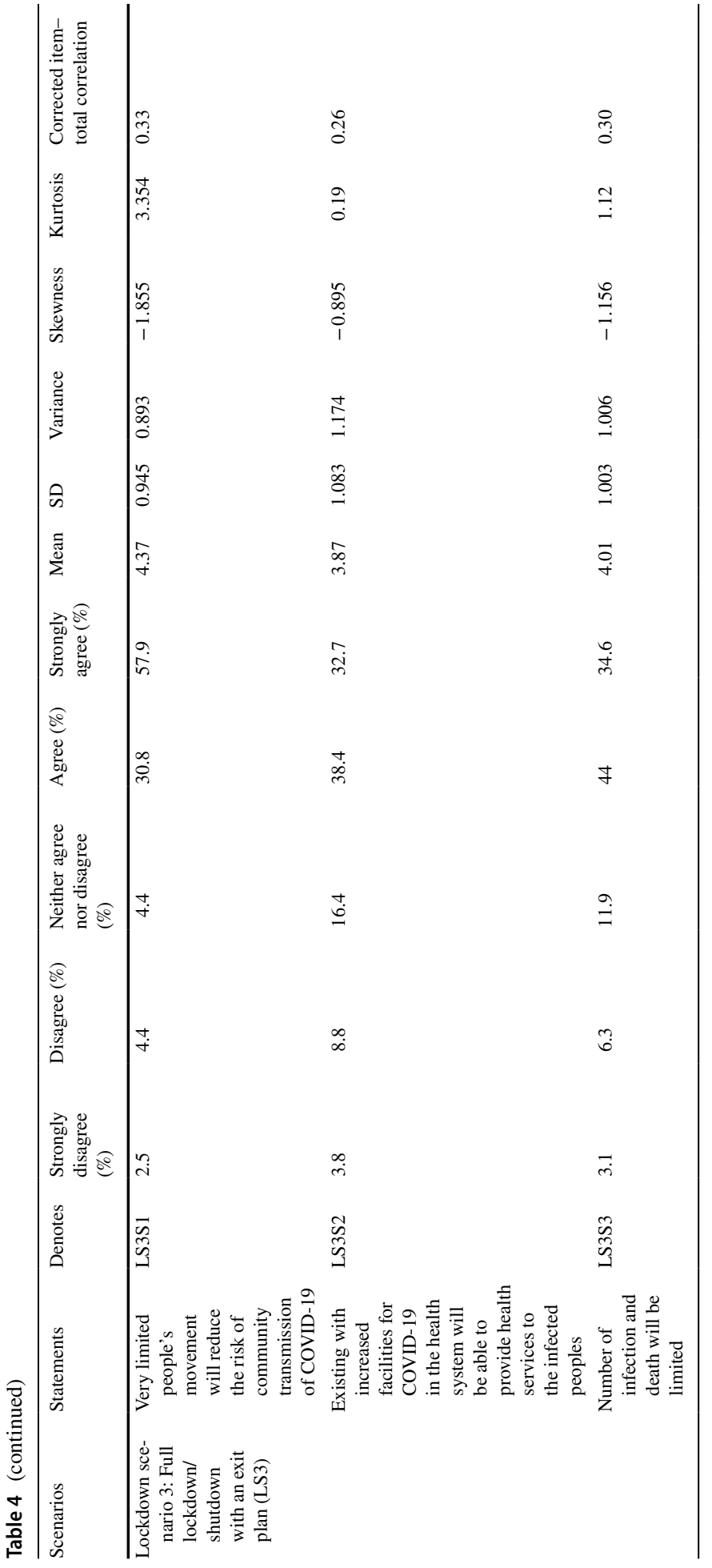




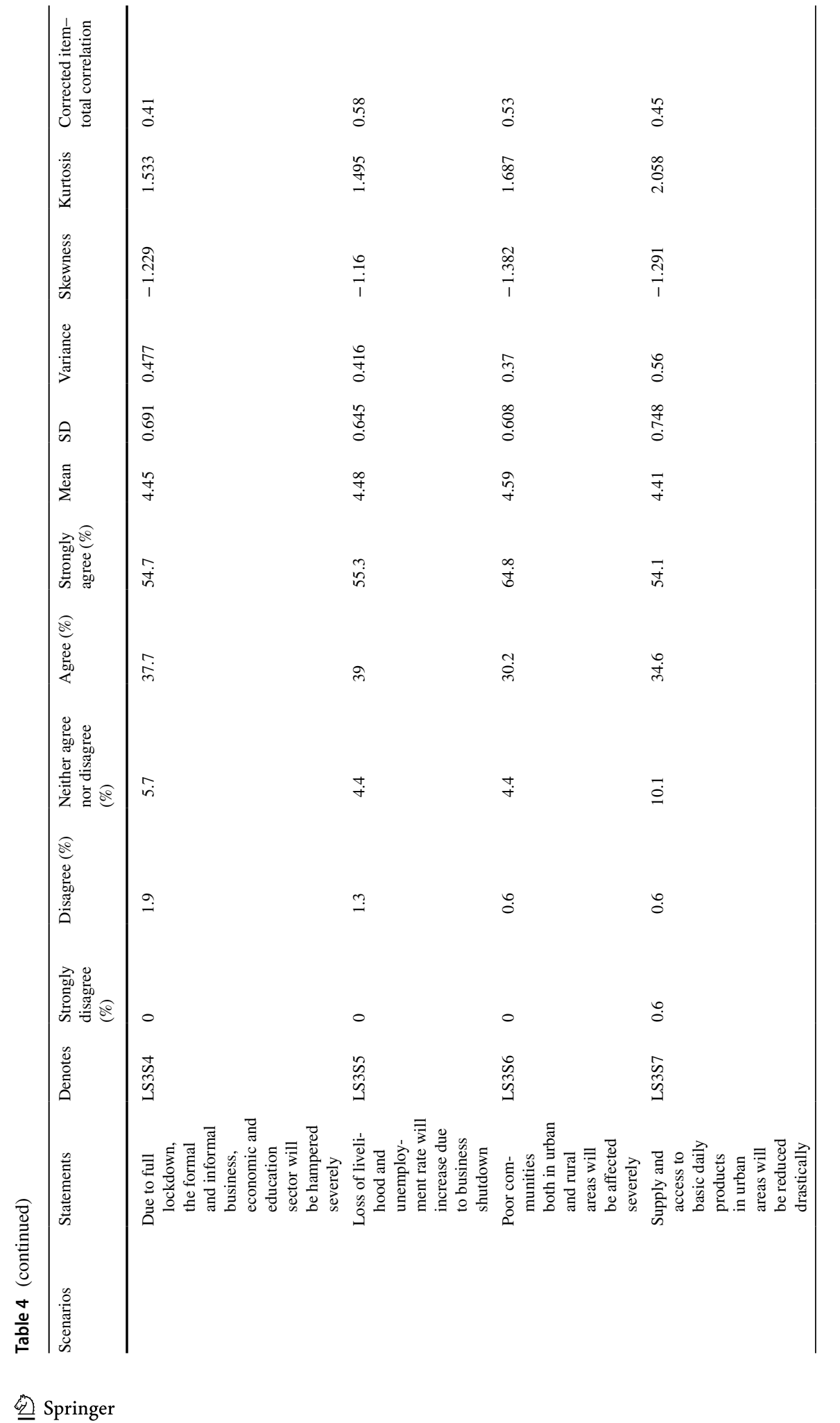




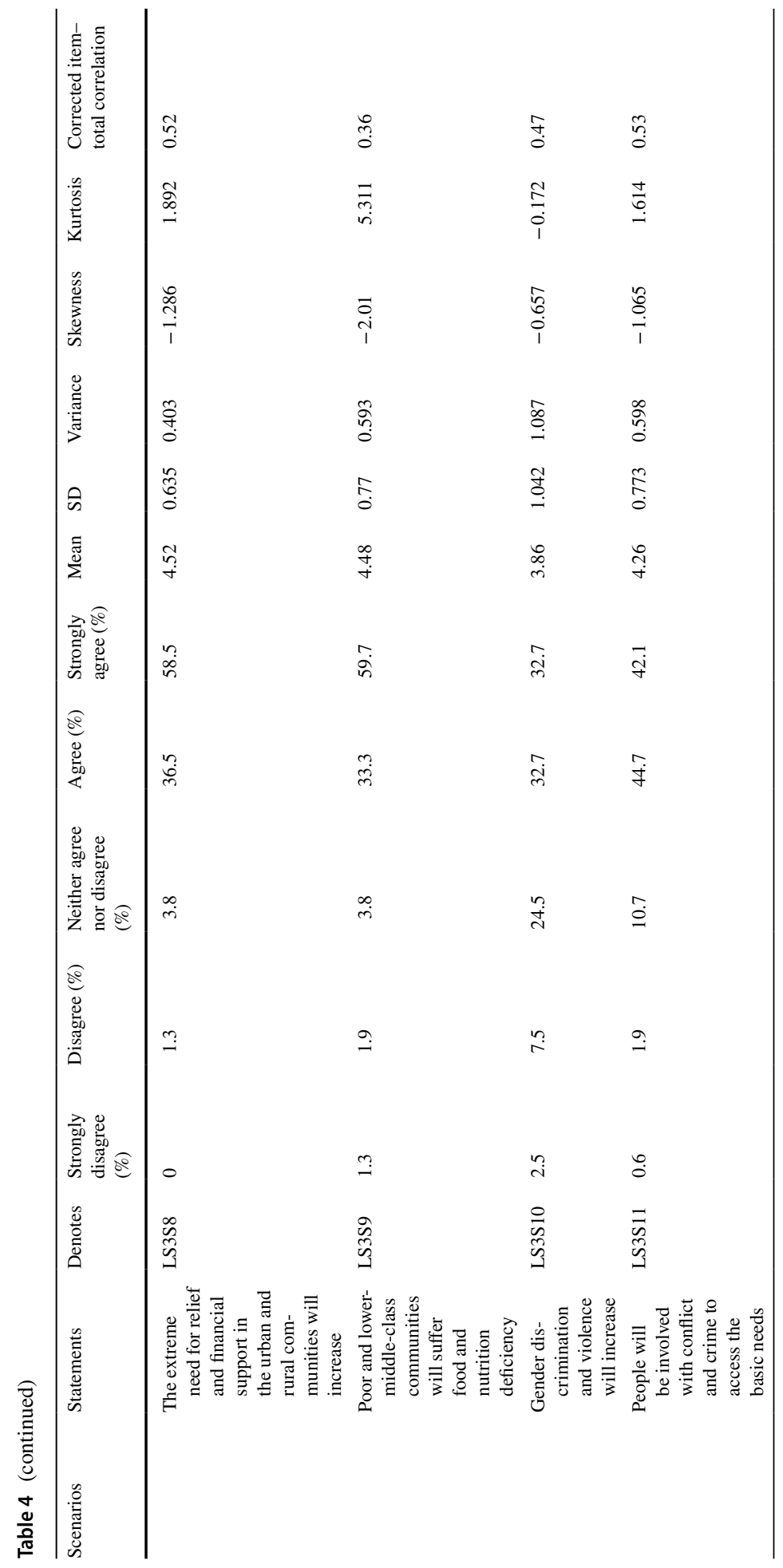




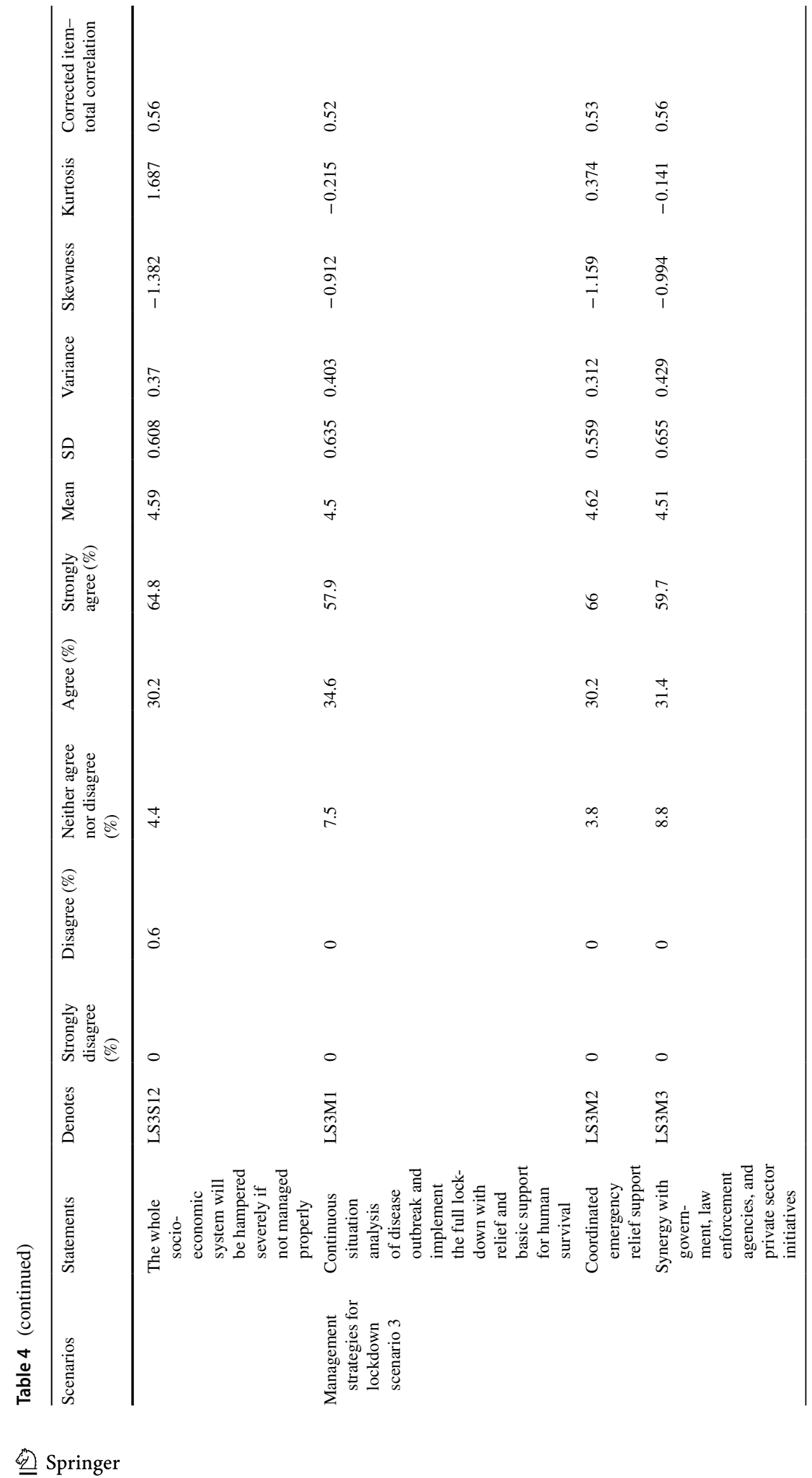




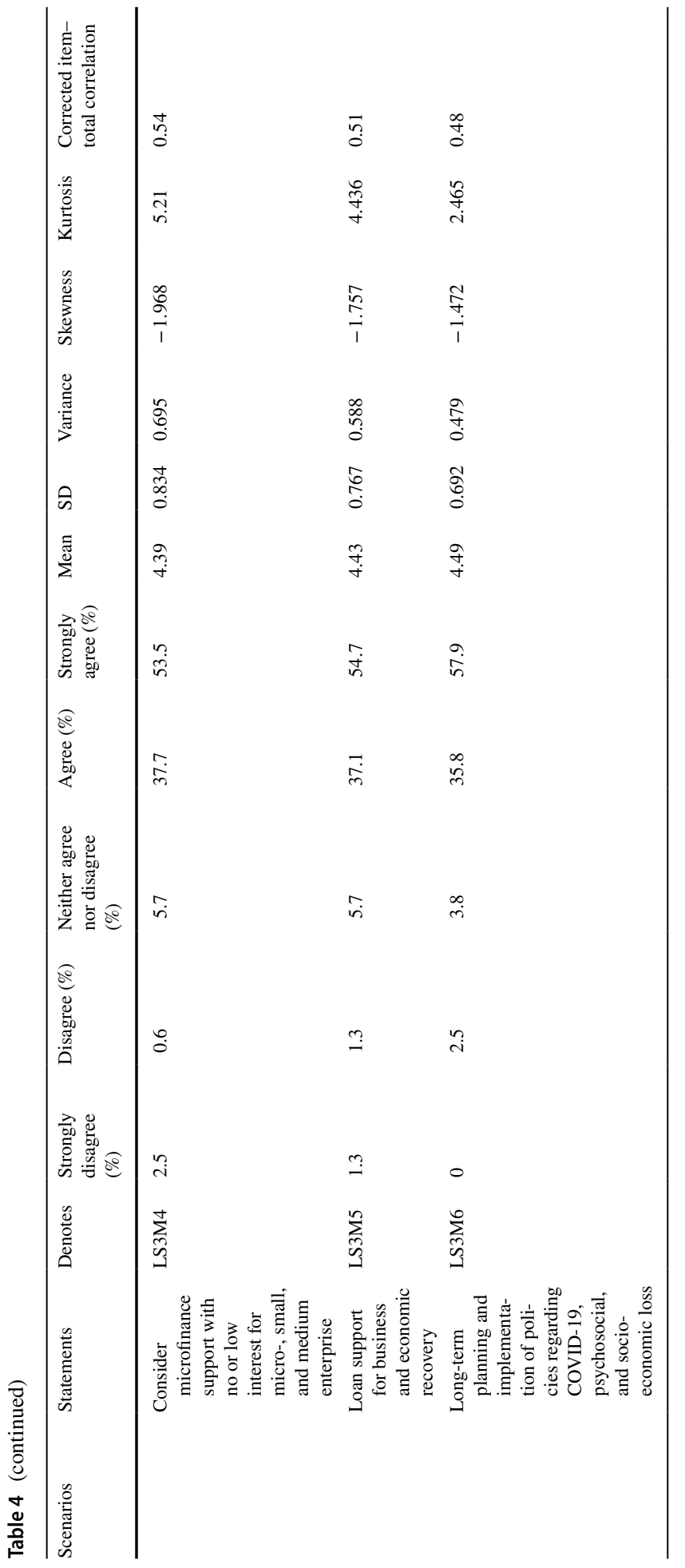


regular life (LS1S1: 0.257); massive movement and a mass gathering of people will be started again (LS1S3: 0.29); community transmission of COVID-19 will increase due to people's movement and mass gathering (LS1S4: 0.298); and the number of infected populations will increase (LS1S5: 0.271). Bangladesh is entering into this scenario without having any signs of flattening the infection curve.

From Pearson correlation analysis, a strong significant positive relationship was observed between people will start moving towards regular life (LS1S1) and the formal and informal economic activities will be started (LS1S2) $(r=0.671, p<0.01)$ (Table 5). Linear regression analysis reveals that the community transmission of COVID-19 will increase due to people's movement and mass gathering (LS1S4) as people will start moving towards regular life (LS1S1, $p<0.01$ ), and crime will rise and more people will die (LS1S15, $p<0.01$ ) exhibited a statistically significant high correlation with the number of infected populations will increase (LS1S5) (Table 6). In addition, more unemployment and loss of livelihood (LS1S13) and more people will die (LS1S15) statistically pose a significant positive impact on an irreversible loss to the economy $(p<0.01)$ of Bangladesh.

\subsection{Impact analysis of lockdown scenario 2}

From CTT analysis, continue the existing partial lockdown (LS1M1: 0.276); limited people's movement will enable low-level community transmission of COVID-19 (LS2S1: 0.281); infection and death rate will increase slowly (LS2S3: 0.214); increased facilities to the healthcare system for COVID-19 treatment will be able to provide health services to the infected peoples (LS3S2: 0.202). From Pearson correlation (Table 5), a significant positive relationship was found between the limited people's movement will enable low-level community transmission of COVID-19 (LS2S1) with the infection, and the death rate will increase slowly (LS2S3) $(r=0.540, p<0.01)$. Also, there will be less supply of basic products for daily use (LS2S7) which posed a significant relationship with the price of most of the basic products will be higher than usual (LS2S8) $(r=0.680, p<0.01)$.

From the linear regression model (Table 6), the association between dependent statements limited people's movement will enable low-level community transmission of COVID-19 (LS2S1, $r=0.599, p<0.01$ ) with poor people will suffer from food and the nutritional deficiency (LS2S9), and gender-based violence will increase (LS2S10). Based on management scenario 2, massive awareness and enforcement of proper lockdown and quarantine initiatives were strongly associated with limited people movement will enable low-level community transmission of COVID-19 (LS2S1, $p<0.05$ ).

\subsection{Impact analysis of lockdown scenario 3}

From the CTT analysis, among 54 statements, the corrected inter-item correlation analysis showed that only one statement has low corrected item-total correlation values $(<0.30)$. This adds existing with increased facilities for COVID-19 in the health system will be able to provide health services to the infected people (LS3S2: 0.255). The highest interitem correlated value is the loss of livelihood and the unemployment rate will increase due to business shutdown (LS3S5: 0.581), while the lowest value is the number of infections and death will be limited (LS3S3: 0.302). In the case of management of scenario 3 , inter-item correlated values are more than 0.478 . The high inter-item correlation was observed in the synergy with government, law enforcement agencies, and private sector 
Table 5 Correlation matrix of people's perception only addressing significant values ( $>0.5)$ (detail matrix is provided in the Supplementary Table 1)

\begin{tabular}{|c|c|}
\hline Statements & Correlations \\
\hline LS1S1 & LS1S2 (.671**), LS1S3 (.505**) \\
\hline LS1S4 & LS1S5 $(.607 * *)$ \\
\hline LS1S5 & $\begin{array}{l}\text { LS1S6 (.653**), LS1S7 (.597**), LS1S8 (.657**), LS1S9 (.650**), } \\
\quad \text { LS1S15 (.536**) }\end{array}$ \\
\hline LS1S6 & LS1S7 (.619**), LS1S8 (.680**), LS1S9 (.544**), LS1S15 (.554**) \\
\hline LS1S7 & LS1S8 (.617**), LS1S9 (.545**), LS1S14 (.521**), LS1S15 (.610**) \\
\hline LS1S8 & LS1S9 (.651**), LS1S15 (.628**) \\
\hline LS1S9 & $\operatorname{LS} 1 S 15(.556 * *)$ \\
\hline LS1S12 & LS1S13 (.726**), LS1S14 (.528**) \\
\hline LS1S13 & LS1S14 (.591**), LS1S15 (.592**) \\
\hline LS1S14 & $\operatorname{LS} 1 S 15(.628 * *)$ \\
\hline LS1M1 & LS1M2 (.628**) \\
\hline LS2S1 & LS2S3 $(.540 * *)$ \\
\hline LS2S5 & LS2S9 (.636**), LS2S11 (.519**) \\
\hline LS2S6 & LS2S9 $(.612 * *)$ \\
\hline LS2S7 & LS2S8 $\left(.680^{* *}\right)$ \\
\hline LS2S9 & $\operatorname{LS} 2 \mathrm{~S} 11(.595 * *)$ \\
\hline LS2S10 & $\operatorname{LS} 3 \operatorname{S} 10(.661 * *)$ \\
\hline LS2S11 & LS2M4 (.506**) \\
\hline LS2M3 & LS2M4 (.690**), LS2M5 (.562**), LS2M6 (.521**) \\
\hline LS2M4 & LS2M6 (.507**) \\
\hline LS3S1 & LS3S3 $\left(.545^{* *}\right)$ \\
\hline LS3S2 & LS3S3 $(.659 * *)$ \\
\hline LS3S4 & LS3S5 (.542**), LS3S6 (.639**) \\
\hline LS3S5 & LS3S6 (.605**), LS3S8 (.523**), LS3S11 (.510**) \\
\hline LS3S7 & LS3S8 $(.534 * *)$ \\
\hline LS3S8 & LS3S12 (.524**) \\
\hline LS3S9 & LS3S12 (.534**) \\
\hline LS3S10 & $\operatorname{LS} 3 S 11(.573 * *)$ \\
\hline LS3S11 & LS3S12 (.522**) \\
\hline LS3S12 & LS3M1 (.552**), LS3M2 (.512**) \\
\hline LS3M1 & LS3M2 (.592**), LS3M3 (.567**) \\
\hline LS3M2 & LS3M3 (.632**), LS3M6 (.547**) \\
\hline LS3M3 & LS3M4 (.527**), LS3M6 (.548**) \\
\hline LS3M4 & LS3M5 (.510**) \\
\hline
\end{tabular}

**Correlation is significant at the 0.01 level (2-tailed)

initiatives (LS3M3: 0.555) and long-term planning and implementation of policies regarding COVID-19, psychosocial, and socio-economic loss (LS3M6: 0.48).

According to the results of the Pearson correlation, there was a statistically significant correlation among scenario 3 where gender discrimination will increase due to COVID-19 outbreak with gender-based violence will increase rapidly $(r=0.661, p<0.01)$. Besides, extremely limited people's movement will reduce the risk of community transmission of COVID-19 with the number of infection and death will be limited $(r=0.545, p<0.01)$. 
Table 6 Estimated model of multiple regression

\begin{tabular}{|c|c|c|c|c|c|c|c|}
\hline & \multicolumn{2}{|c|}{$\begin{array}{l}\text { Unstandardized } \\
\text { coefficients }\end{array}$} & \multirow{2}{*}{$\begin{array}{l}\text { Standardized } \\
\text { coefficients } \\
\text { Beta }\end{array}$} & \multirow[t]{2}{*}{$t$} & \multirow[t]{2}{*}{ Sig. } & \multicolumn{2}{|c|}{$95.0 \%$ confidence interval for $B$} \\
\hline & $B$ & SE & & & & Lower bound & Upper bound \\
\hline \multicolumn{8}{|c|}{ Regression model 1: Dependent variable: LS1S4 $\left(R=0.712, R^{2}=0.508\right)$} \\
\hline (Constant) & 0.127 & 0.395 & & 0.321 & 0.749 & -0.653 & 0.906 \\
\hline LS1S5 & 0.528 & 0.086 & 0.462 & 6.124 & 0 & 0.357 & 0.698 \\
\hline LS1S13 & 0.269 & 0.069 & 0.285 & 3.9 & 0 & 0.133 & 0.405 \\
\hline LS1M3 & 0.191 & 0.057 & 0.2 & 3.366 & 0.001 & 0.079 & 0.303 \\
\hline LS1S15 & -0.253 & 0.076 & -0.281 & -3.321 & 0.001 & -0.403 & -0.102 \\
\hline LS1S1 & 0.094 & 0.034 & 0.17 & 2.754 & 0.007 & 0.027 & 0.162 \\
\hline LS1S7 & 0.169 & 0.073 & 0.188 & 2.331 & 0.021 & 0.026 & 0.312 \\
\hline \multicolumn{8}{|c|}{ Regression model 2: Dependent variable: LS2S1 $\left(R=0.599, R^{2}=0.359\right)$} \\
\hline (Constant) & 1.342 & 0.574 & & 2.338 & 0.021 & 0.208 & 2.476 \\
\hline LS2S3 & 0.538 & 0.069 & 0.522 & 7.812 & 0 & 0.402 & 0.674 \\
\hline LS2S10 & 0.184 & 0.068 & 0.179 & 2.696 & 0.008 & 0.049 & 0.319 \\
\hline LS2S9 & -0.212 & 0.085 & -0.168 & -2.504 & 0.013 & -0.379 & -0.045 \\
\hline LS2M3 & 0.218 & 0.106 & 0.138 & 2.048 & 0.042 & 0.008 & 0.428 \\
\hline \multicolumn{8}{|c|}{ Regression model 3: Dependent variable: LS3S4 $\left(R=0.695, R^{2}=0.483\right)$} \\
\hline (Constant) & 0.839 & 0.395 & & 2.124 & 0.035 & 0.059 & 1.618 \\
\hline LS3S6 & 0.546 & 0.084 & 0.481 & 6.52 & 0 & 0.381 & 0.712 \\
\hline LS3S5 & 0.252 & 0.081 & 0.235 & 3.098 & 0.002 & 0.091 & 0.413 \\
\hline LS3M4 & 0.171 & 0.055 & 0.206 & 3.115 & 0.002 & 0.062 & 0.279 \\
\hline LS3M2 & -0.167 & 0.084 & -0.135 & -1.992 & 0.048 & -0.334 & -0.001 \\
\hline
\end{tabular}

For management purposes, synergy with government, law enforcement agencies, and private sector initiatives with coordinated emergency relief support $(r=0.632, p<0.01)$. Also, microfinance support to small and medium enterprises is required for recovery (LS3M4, $p<0.05)$.

\subsection{Management strategies considering lockdown scenarios}

For management strategies of scenario 1, deep analysis of the situation should be carried out and go for full lockdown with relief support to the poor and most vulnerable are urgently needed for decision-making in the county due to the rapid community transmission of COVID-19 $(p<0.01)$. First of all, the government should come up with a comprehensive strategic plan accompanied by non-governmental and social organizations and law enforcement to analyse the spread of the virus, identifying the most vulnerable hosts, properly tracked the movement of general people, precise estimation of economic losses from different financial and industrial sectors, educational diminutions and professional and informal employment disruption to picture an integrated scenario of the current situation and future predictions by which the revival of the negative aspects of the country could be managed. There must be two types of the strategic plan on under the category of the emergency response plan (short-term) by ensuring basic supplies to all citizens who are in real needs, motivate and/or force the people to abide by the COVID-19 guidelines by the GoB 
and WHO, prepare a complete but robust list of vulnerable population in terms of COVID19 spreading, co-morbidities, and economic stress, activate all the local wings of the GoB such as local government representatives at the village level, and construct a COVID-19 response task force to monitor and handle the country situation through application of information and communication technologies (ICT). The government should implement those plans with proper timing, transparency, and resources.

The GoB has already been taking a lot of initiatives to tackle COVID-19 pandemic, but there seems lacking proper risk assessment and weak coordination among stakeholders from medical to social welfare. Another plan must be focused on the reconstruction or rebuild (long-term) and must follow the guidelines of the Sendai framework. The Sendai framework for disaster risk reduction 2015-2030 recognizes health at the heart of disaster risk management (DRM) at the global policy level (Wright et al. 2020). This Sendai Framework has given the rise of the health-emergency disaster risk management (HealthEDRM) framework an umbrella term used by WHO (2019). Health-EDRM thus refers to the "systematic analysis and management of health risks, posed by emergencies and disasters, through a combination of (1) hazard and vulnerability reduction to prevent and mitigate risks, (2) preparedness, (3) response and (4) recovery measures" (Djalante et al. 2020). This also includes build back the healthcare sector, industrial sector, education, agriculture, research, environment, and finance.

However, deep research complied with massive surveillance could help in making decisions whether the lockdown must be further carried on or not and this must have to be based on evidence. Miscommunication and miscalculation of the strategy may trigger worsen the situation. Communicating the disease risk in the local language is also necessary to increase awareness about the diseases. Moreover, in Sects. (3.5.1-3.5.3) we have analysed emergency management issues including short to medium-term measures as well as long-term management strategies of COVID-19 pandemic lockdown scenarios in Bangladesh based on our research outcomes.

\subsubsection{Management considerations for lockdown scenario 1}

"Lockdown" is an unfamiliar word or term to the people of Bangladesh. According to scenario 1, a partial lockdown is a hoax. People recommended to use a more familiar term "curfew" (legal section 144) to maintain strict and there is no alternative to reduce COVID19 transmission. In Bangladesh, section 144 of The Penal code 1860 prohibits assembly of five or more people, holding of public meetings, and carrying of firearms and this law can be invoked for up to two months (MinLaw/GoB 2019). This law could have been a much more effective strategy to contain the infection.

In total, $78.6 \%$ of the participants agreed that community transmission of COVID-19 will increase due to the people's movement and mass gathering, $57.9 \%$ agreed to continue the existing partial lockdown, whereas approximately $73 \%$ of respondents agreed that deep analysis of the situation is required and go for full lockdown with the relief support to the poor and the most vulnerable. Overall, the participants had a positive view about lockdown scenario 1 to possibly spread out of COVID-19 at the community level. Many people expressed their disappointment towards the extreme corruption of the healthcare sector and that it has collapsed before the COVID-19 pandemic.

Respondents advocated the government to consider biomedical waste management for reducing further environmental transmission and that efficient incinerator to be built for hospital waste management. However, the responders also suggested the government to 
sustain the retail and wholesale kitchen market/bazaar of any area maintaining the health guideline and social distancing. This approach could have positive feedback as already experience in different Upazilas in Bangladesh with the help of local administrative authorities, magistrates, and police forces.

After the 30 days of the partial lockdown, the Federation of Bangladesh Chambers of Commerce and Industries recommended the opening of the industrial sectors with some guidelines (FBCCI 2020). Moreover, the FBCCI taskforce demanded the COVID-19 incentive financial package in a more gettable way from the GoB. It could be a very crucial decision to be taken considering the COVID-19 contagions and the business development to protect the exports. To maintain livelihood, industrial workers resumed their work from 25 April 2020. However, the GoB weakened the lockdown and resumed the industrial activities without proper guidelines or the scientific basis for such a risky decision. The question is why the GoB was in hurry to weakening the lockdown and withdraw it without eradicating the disease? Predictably, there might be a strong business/financial association to withdraw the lockdown when life and livelihood matters for the poor and middle-class people and to run the country's economy.

Although GoB provided healthcare guidelines and social distancing during work, the infection rates surged significantly among the workers in the industrial zones. Most of the COVID-19 clusters are majorly distributed in Dhaka city, Chittagong city, Narayanganj, Cumilla, Gazipur, and the peripheral cities (IEDCR 2020; TBS News 2020b). Finally, this study confirms that the withdrawal of the partial lockdown will not become positive in terms of COVID-19 management in Bangladesh, because still, we do not have enough evidence even after the 65 days of lockdown that the transmission is reducing from the peak.

\subsubsection{Management considerations for lockdown scenario 2}

Overall, the participants had a positive view about lockdown scenario 2 to stop/slow down the spreading out of COVID-19 pandemic in Bangladesh. In total, 52.2\% of respondents in this study agreed that existing health facilities will not be able to provide adequate services to the number of COVID-19 patients due to limited community transmission, while $67.9 \%$ strongly agreed that there will be a need for emergency food and financial support to the poor communities. About $72.5 \%$ strongly agreed that emergency relief to the poor communities in both urban and rural areas should be provided ensuring transparency.

Around 34 million people, or $20.5 \%$ of the population, live below the poverty line and based on the current rate of poverty reduction, Bangladesh is projected to eliminate extreme poverty by 2021 (Chaudhury 2018). Yet, as COVID-19 pandemic hit the country within 2 weeks Poverty rate in Bangladesh rose to $40.9 \%$ as $25 \%$ of family incomes fell (The Financial Express 2020a). So, it was the choice between life versus livelihood (Hussain 2020). The poor community always lacks food and nutrition due to the injustice and corruption by the local or regional level of political stakeholders in Bangladesh. By nature, people of Bangladesh are quite unaware and kind of ignorant or does not like to abide by rules. Moreover, the public is not confident somehow with the administrative decisions, policies, and their implementation of COVID-19 emergency response such as lockdown on their livelihoods. There was also a lack of coordination among the different government stakeholders to tackle emergency healthcare and crisis management in the field. For instance, people usually made different excuses to go outside and a regular crowd was common in the kitchen market, streets, and small bazaars. Only the government, 
semi-government, autonomous institutes/organizations, and educational institutions were maintaining the rules/guidelines.

This situation is well visualized in different mass media that people are in movement for relief, road blockage, corruption by the government representatives, mismanagement in relief distribution, biases to party supporters, bureaucratic administrators to look after the response activities, and so on. Likewise, the potential danger of COVID-19 pandemic from the very beginning has been overlooked by the people due to the presence of misinformation in the social and mass media that it was general flue, and that the virus cannot infect in a humid country like Bangladesh. So, the government should try to implement a stringent policy of risk communication and media communication during this emergency to the most vulnerable communities. The vulnerable groups such as disable and disadvantaged persons, young children and orphans, and aged citizens should be taken under protection for their well-being (UNDP 2020a). Right now, doctors, bankers, grocers, police, and armed forces are the most vulnerable profession to the COVID-19 infection. Until 25 May 2020, 24\% doctors, 16\% nurse and 6\% frontline healthcare workers were COVID19-infected. Of the infected, 15 police personnel had so far died, while more than 5000 others are in either isolation or in quarantine (The Daily Star 2020).

Although the extension of partial lockdown was not a solution in Bangladesh, it could have been an effective option continued to slower the infection rate. The lockdown should have been partially continued with necessary financial support for the vulnerable. It would have been a crisis for a short time, but it would be a saviour for the future (Shammi and Bodrud-Doza 2020). However, to run the economy, the hotspots of the infection and the cluster areas could remain lockdown, while economic activities could have maintained by strongly abiding public health guidelines and social distancing. Moreover, for the next couple of years, it will be extremely hard for the country especially as far as the financial issues are concerned to achieve the current development as well as SDG targets and reaching to middle-income countries (UNDP 2020a). GoB should declare the delayed beginning of its 8th five-year national plan due to the COVID-19 pandemic as a large part of it seems to be irrelevant at this stage, according to his proposals (The Financial Express 2020b). Increasing surveillance as well as the reallocation of the budget, the distribution of direct cash, and private sector engagement could be some of the options to alleviate the crisis.

\subsubsection{Management considerations for lockdown scenario 3}

In total, $54.7 \%$ of the respondents in this study agreed that due to full lockdown, the formal and informal business, economic and education sector will be hampered severely. $64.8 \%$ agreed that the poor and vulnerable communities both in urban and rural areas will be affected severely. For management purposes, $66 \%$ of the respondents thought that coordinated emergency relief support is required. Overall, the respondents had a positive viewpoint about lockdown scenario 3 due to the COVID-19 outbreak in Bangladesh. If we have no other options, a strategic plan and policy should be taken for the revival of the health sector, economy, and education. It is speculative that a full lockdown might end up with famine and starvation. According to the World Bank report (2020) prolonged and broad national lockdowns will bring a negative growth rate of the economy in Bangladesh and other South Asian countries in 2020 due to the COVID-19 pandemic. This negative growth rate will continue in 2021 with growth projected to hover between 3.1 and $4.0 \%$, down from the previous $6.7 \%$ estimate. 
A more serious issue that will arise due to the progress of the pandemic is the rate of suicide as a long-term effect on the vulnerable population due to fear and economic hardships (Mamun and Griffiths 2020). Preventing suicide and counselling mental health issues are therefore be considered by the authority (Gunnell et al. 2020). Moreover, the authority should take proper steps to meet the basic emergency services and maintain the basic supply-demand of the daily needs of urban and rural people by transporting the crops and vegetable production from the farms. Due to the lockdown, the farmers should not face any crop loss and they should be also brought under the financial and other stimulus plans so they can continue their productions for the future. If the needed government should give them free seeds, fertilizers, electricity for irrigations, and water and other incentives such as no-interest agricultural loans for future food security. The government already declared a financial recovery package with a clear disparity towards the agricultural sector. The financial stimulus package mainly focused on large and export-oriented businesses such as the readymade garment sector (RMG). It seems that this package has arrived a little earlier without any participatory strategic assessment. A strong collaborative need-based assessment is required to tackle the short-term and long-term needs to properly distribute the stimulus package. In this emergency response, the local government must have to come forward with full strength and capacities to implement the work plan for the GoB.

\subsection{Overall relationship assessment of COVID-19 impact on effective management, policy implications, governance, and sustainability}

For overall relationship assessment for effective management of policy implications, governance, and developmental effects, PCA (Fig. 4), cluster analysis (Fig. 5), and Pearson correlation (Table 5 and Supplementary Table 1) significantly show the relationships.

\subsubsection{Interpretation of PCA for short-term and long-term lockdown scenario analysis}

PCA showed a significant level of controlling factors in Bangladesh COVID-19 pandemic and how these statements are associated with the various scenarios (Table 7). Nine principal components (PCs) were originated based on standard eigenvalues (surpassed 1) that extracted $52.195 \%$ of the total variance as outlined in Table 7. However, before PCA applying in the tested data, the Kaiser-Meyer-Olkin (KMO) and Bartlett's tests of Sphericity were conducted to appropriateness for this study. The findings of the KMO value in this research were $0.8(>0.50)$, the confidence level of Bartlett's sphericity (BS) test was zero at $p<0.01$, suggesting the tested data were fit for PCA analysis.

The scree plot was used to identify the number of PCs to be retained to the understanding of the inherent variable structure (Fig. 4). The loading scores were classified into three groups of weak (0.50-0.30), moderate (0.75-0.50), and strong (>0.75), respectively (Liu et al. 2003; Islam et al. 2017). The PC1 (first) explained $11.074 \%$ of the variance as it covered a significance level of strong positive loading of the lockdown scenarios and management 2 in Bangladesh (LS1S5: 0.81 and LS1S6: 0.82). Similarly, moderate positively loaded of the lockdown scenarios 1 in Bangladesh (LS1S4: 0.608 LS1S7-S9: 0.741-0.795).

The PC2 (second) explained $8.305 \%$ of the total variance and was loaded with moderate positive loading of lock drown scenarios 3 (LS3S4-9: 636-0.706 and LS3S12: 0.615). The PC3 (third) elucidated $8.305 \%$ of the variance and was strong positively loaded of massive awareness and enforcement of proper lockdown and quarantine initiatives (LS2M3: 0.836) and provide emergency relief to the poor communities both 


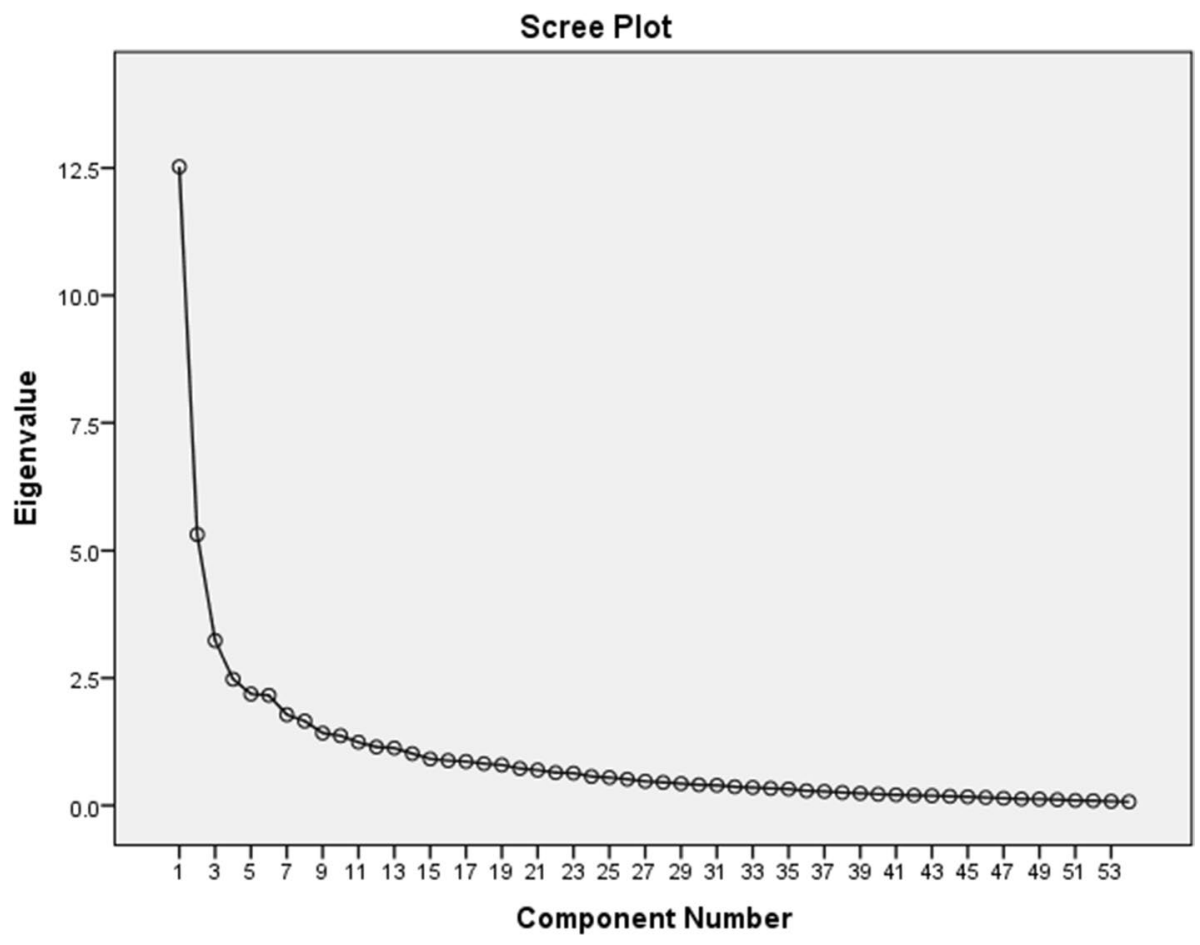

Fig. 4 Scree plots of the eigenvalues of PCA

in urban and rural areas ensuring transparency (LS2M4: 0.789). Furthermore, management scenario 2 and scenario 3 were observed moderate positive loading of PC3 (LS2M2: 0.637; LS2M5: 0.597, LS2M6: 0.642 and LS3M3: 0.547). The PC4 (four) accounted for $6.073 \%$ of the total variance and was strong positively loaded of poor people who will suffer food and the nutritional deficiency (LS2S9: 0.855) and moderately loaded in scenario 2 (LS2S5-S6: 0.652-0.657 and LS2S11: 0.637). The PC5 (five) explained $5.072 \%$ of the variance and was strong positively loaded of deep analysis of the situation and continue this existing partial lockdown (LS1M2: 0.779) and with moderately loaded in the management scenario 1 (LS1M1: 0.747 and LS1M3: 0.686). PC6 (Six) accounted for 4.646 of the total variances and were strong positive loading of existing with increased facilities for COVID-19 in the health system will be able to provide health services to the infected peoples and number of infection and death will be limited (LS3S2: 0.812 and LS3S3: 0.863) and with moderately loaded of very limited peoples movement will reduce the risk of community transmission of COVID-19 (LS3S1: 0.689). PC7 (seven) explained for $4.419 \%$ of the variance and was strong positively loaded with gender-based violence will increase (LS2S10: 0.796) and gender discrimination will increase (LS3S10: 0.863). PC8 (eight) was responsible for $4.301 \%$ of the variance and was strong positively loaded with people will start moving towards regular life and formal (LS1S1: 0.866) and informal economical activities will be started (LS1S2: 0.836) and moderate positively loaded of massive movement and a mass gathering of people will be started again (LS1S3: 0.652). 


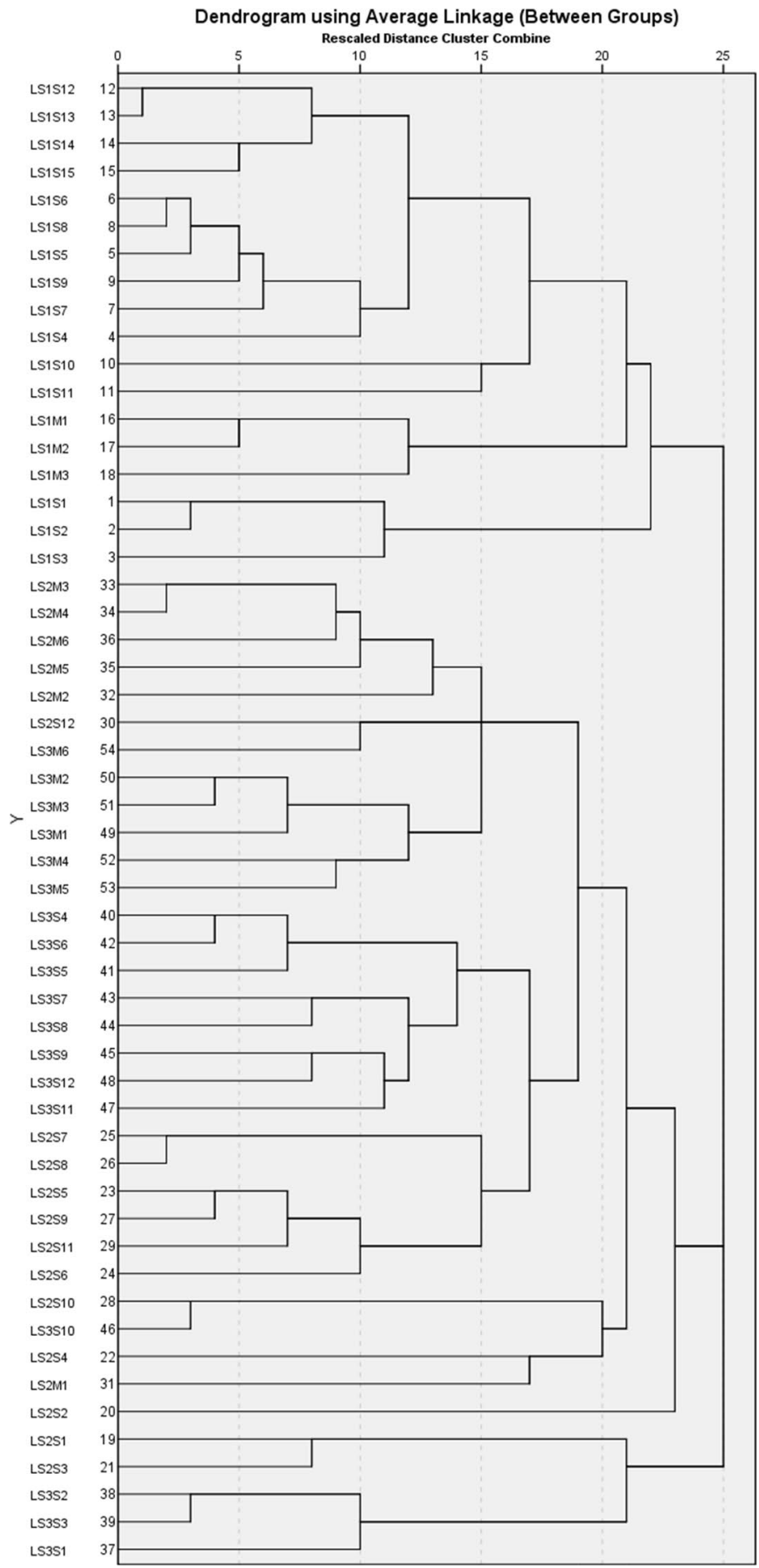

Fig. 5 Dendrogram showing the clustering of people's perceptions of different scenarios 


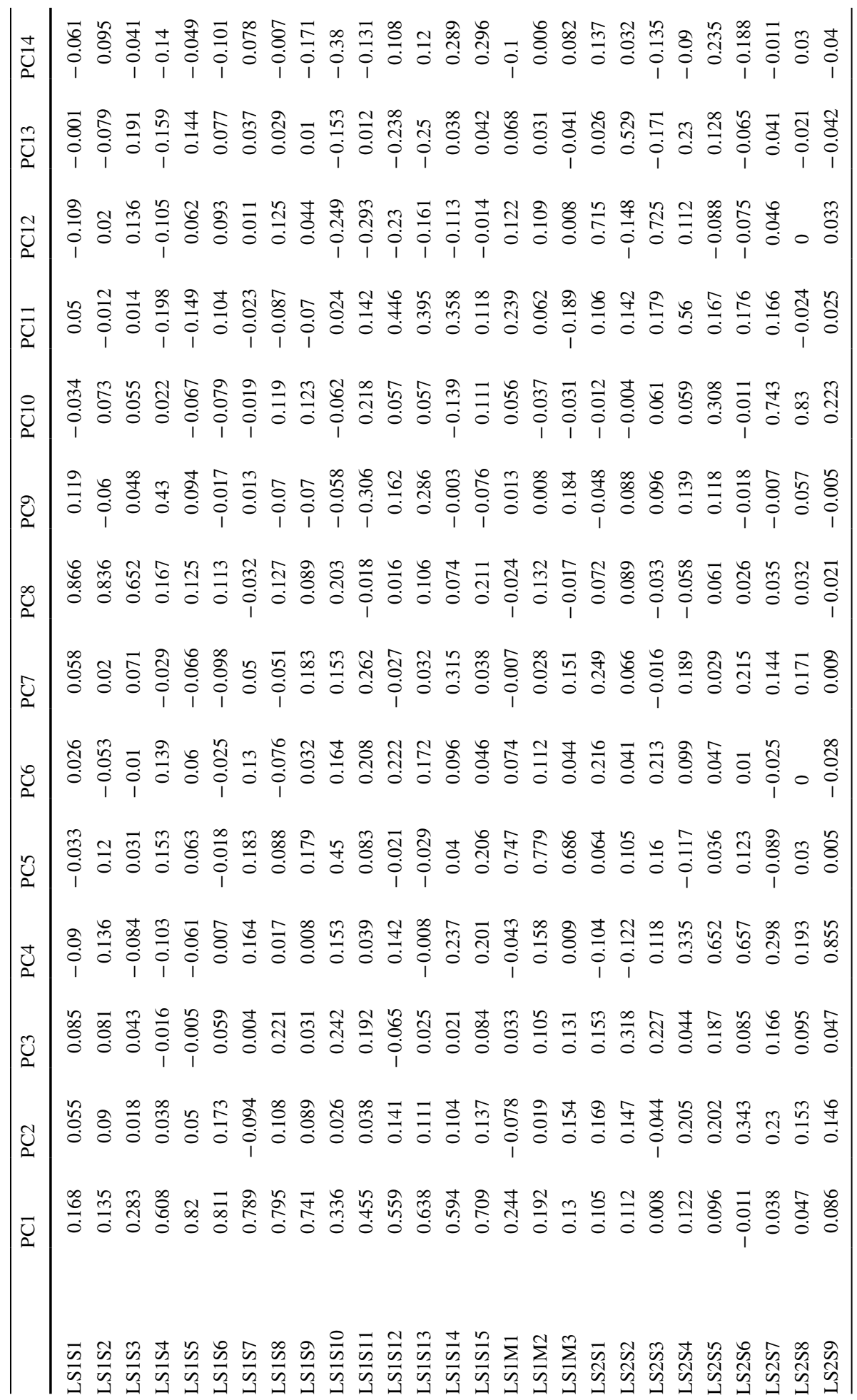




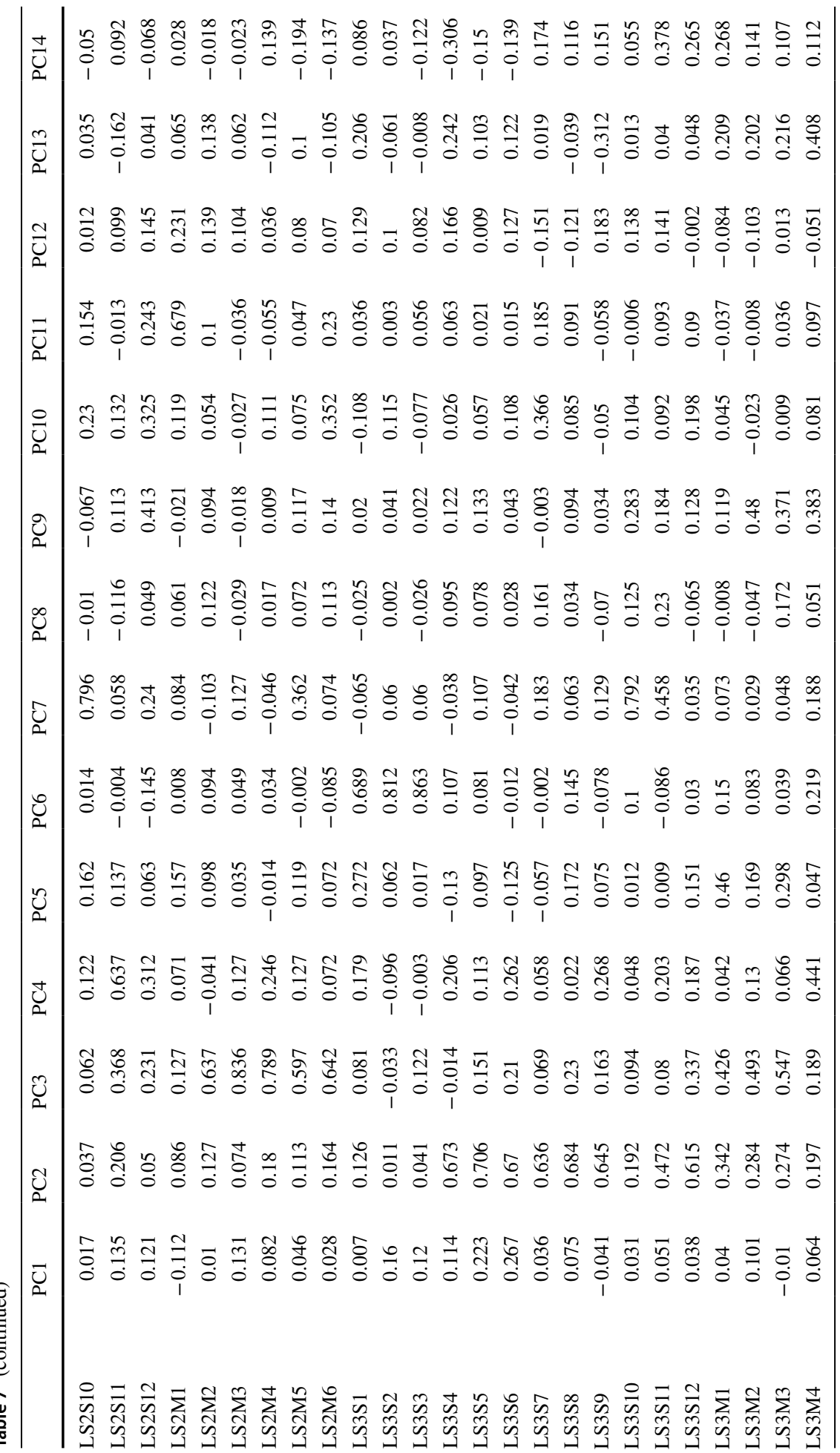




\begin{tabular}{|c|c|}
\hline$\underset{U}{ \pm}$ & 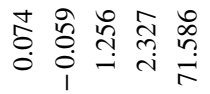 \\
\hline$\stackrel{m}{\Omega}$ & 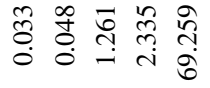 \\
\hline$\frac{1}{2}$ & 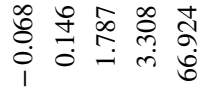 \\
\hline $\bar{v}$ & 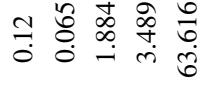 \\
\hline Ů & 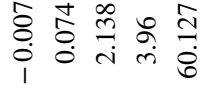 \\
\hline ঠે & 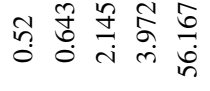 \\
\hline$\bigcup_{0}^{\infty}$ & 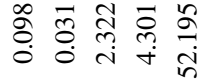 \\
\hline U. & 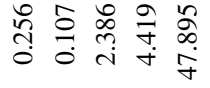 \\
\hline ְֶ. & 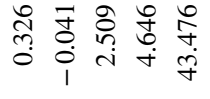 \\
\hline 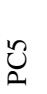 & 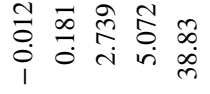 \\
\hline ¿ & 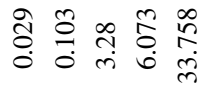 \\
\hline U్ర & 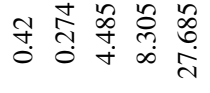 \\
\hline Ũ & 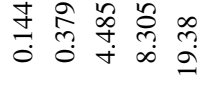 \\
\hline$\vec{\nu}$ & 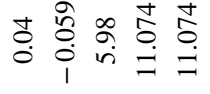 \\
\hline & 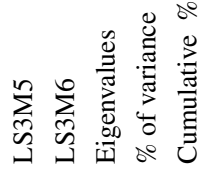 \\
\hline
\end{tabular}




\subsubsection{Interpretation of CA for short-term and long-term lockdown scenario analysis}

Cluster analysis (CA) further recognized the total status of scenario variations and how these scenarios influence the socio-economic and development impacts (Fig. 5). All the statements were categorized into five major classes: cluster 1 (C1), cluster 2 (C2), cluster 3 (C3), cluster 4 (C4), and cluster 5 (C5). C1 consisted of five sub-clusters of $\mathrm{C} 1-\mathrm{A}, \mathrm{B}$, and $\mathrm{C}$; $\mathrm{C} 1-\mathrm{A}$ composed of an irreversible loss to the economy and More people will die (LS1S12-LS1S15) C1-B comprised of Community transmission of COVID-19 will increase due to people's movement and mass gathering and Panic will rise in the mass communities (LS1S4-S9). C1-C is comprised of the possibility of the full lockdown of the whole system again and No basic services will be available (LS1S10 and LS1S11). C2 consisted of three sub-clusters of C2-A, and B. C2-A consists of continue the existing partial lockdown and deep analysis of the situation and go for full lockdown with relief support to the poor and most vulnerable (LS1M1-M3) C2-B consists of People will start moving towards regular life and massive movement and a mass gathering of people will be started again (LS1S1-LS1S3). C3 consisted of three sub-clusters of C3-A, B, and C. C3-A contained an existing increase in the health facilities involving private sectors and implement inclusive sustainable quick plan and policies to revive the economy and employment (LS2M2-M6). C3-B consisted of lack of support and improper management will lead to the psychosocial and socio-economic crisis and Long-term planning and implementation of policies regarding COVID-19, psychosocial, and socio-economic loss (LS2S12 and LS3M6), while C3-C composed of Continuous situation analysis of disease outbreak and implement the full lockdown with relief and basic support for human survival and loan support for business and economic recovery (LS3M1-M5).

Cluster 4 consisted of three sub-clusters of C4-A due to full lockdown, the formal and informal business, economic, and education sector will be hampered severely, loss of livelihood and unemployment rate will increase due to business shutdown, and poor communities in both urban and rural areas will be affected severely (LS3S4-6); C4-B supply and access to basic daily products in urban areas will be reduced drastically, the extreme need for relief and financial support in the urban and rural communities will increase, and people will be involved with conflict and crime to access the basic needs (LS3S7-12); and C4-C there will be less supply of basic products for daily use and price of most of the basic products will be higher than usual (LS2S7-S8). C4-D indicates poor people living from hand to mouth will be severely affected and the formal education system will be hampered. C5 consisted of two sub-clusters of C5-A, B, and C. C5-A contained gender-based violence will increase and gender discrimination and violence will increase LS2S10 and LS3S10. C5-B comprised of limited people's movement will enable low-level community transmission of COVID-19 and infection and death rate will increase slowly (LS2S1-S3). C5-C contained limited people movement will reduce the risk of community transmission of COVID-19 and the number of infections will be limited LS3S1-S3. 


\subsubsection{COVID-19 affecting policy implications, governance, and development goals- management strategy for sustainability}

The COVID-19 pandemic has the most effects on vulnerable populations, ranging from good health and well-being (SDG 3) to quality education (SDG 4) worldwide. Disruptions in the routine health care, poverty, and access to food and nutrition will culminate into unavoidable shocks and health system collapse which will increase child mortality and maternal deaths as well as many unwanted deaths (Roberton et al. 2020). The crises in achieving clean water and sanitation targets (SDG 6), weak economic development and the absence of decent jobs (SDG 8), overall inequality (SDG 10), and above all, no poverty (SDG 1), and food insecurity (SDG 2) will be aggravated in many developing countries. The World Bank reports that about 11 million people will be forced into poverty by the crisis (WEF 2020b). According to UNDP (2020b), revenue losses in developing countries are estimated to reach $\$ 220$ billion. The losses would be consequences of the education, human rights, and, in the most extreme cases, fundamental food security and nutrition, with an estimated $55 \%$ of the global population not having access to social protection. Wider socio-economic effects will likely continue for several months to years across the world which will also significantly impact the economy of Bangladesh. Global food security will be hampered as one-third of the world's population is in lockdown (Galanakis 2020). Both the import of important goods and exports related to the readymade garment sector and others likely will be affected for income and employment.

Financial protection during outbreak matters. At the initial stage of the COVID-19 epidemic, out-of-pocket expenditure posed a substantial financial burden for the poor populations with severe symptoms, even for those under coverage by the social health insurance scheme (Wang and Tang 2020). People marginally above the poverty level particularly low-income families, daily and informal low wedge earners, ethnic community groups, people with disabilities, and returnee migrant workers are already started falling below the poverty line due to loss of income and employment. BRAC an international Bangladeshi NGO survey report confirmed to increase a $60 \%$ rise in poverty amidst the COVID-19 pandemic (BRAC 2020). The intake of foods, vegetables, and herbs can boost the immune system against the infection disease, while it can stimulate the transmission through the food chain (Galanakis 2020). Again, the lack of food will rise to malnutrition, hunger, and famine. Approximately 265, million people worldwide will be suffering from acute hunger projected by the UN World Food Programme (WEF 2020c).

Ready-made garment (RMG) sector is going to suffer a serious shortfall as until 24 March 2020, orders of RMG products from 738 garment factories worth US\$ 2.4 billion was cancelled. This is the sector where almost 4 million low-income people-of whom over $85 \%$ are women-work and another similar number of people indirectly depend on the downstream and upstream services required by the RMG value chain (Dhaka Tribune 2020a). As the lockdown continues to ensure public health and safety, many RMG workers already lost their jobs and did not receive their salary of the previous months, some of them have been sacked already. Food security and social and economic recovery package of the government should focus on immediate response during the lockdown period and outbreak and post-lockdown support mechanisms. In this condition, middle-income families are relying on their savings available. The negative coping mechanism includes skipping meals and nutrition and distressing the whole family. In the prolonged lockdown scenario, they need government and other support measures to continue their lives under lockdown. 
Due to lockdown, the agricultural products in the urban areas are selling at a high price, while the farmers are not getting the fair price of the product in agricultural districts. It was due to the proper decisions and policy of the GoB that Aman paddy was timely harvested ensuring the safety of migrant workers. Otherwise, it would have likely imposed a bigger social and economic implications such as heavy rainfall triggering natural flash flooding. Moreover, due to the lockdown transport of animal, poultry and fish feed are hampered. Likewise, due to the closure of local restaurants and hotels, the market demand for eggs and chicken had lowered. All this will likely impose further impacts on food production and crop supply chains. To protect the country from famine, the Bangladesh government should consider the stimulus package for the farmers with $2 \%$ agricultural loan to continue cropping and agricultural production.

Receiving education has stopped for most of the students in Bangladesh. The government of Bangladesh postponed all academic and public exams until the indefinite period, considering the growing public concern. Distance learning education of the national curriculum through air transmission in the national TV had started though. While urban children can attend virtual classes through the internet, rural and marginalized children are deprived due to limited resources. Students from marginalized backgrounds particularly with disabilities will lose out more on their education. Considering this, GoB should prepare special educational package including counselling for marginalized and disadvantaged students.

\subsubsection{GoB's decision to withdraw the partial lockdown on 30th May 2020 and its implications}

The severe infection of COVID-19 pandemic has devastated the healthcare systems across the globe from a shortage of N95 masks, and personal protective equipment (PPEs) for the healthcare workers and putting occupational health risk, allocations of ventilators, ICUs, and hospital beds to a patient who can benefit most from treatment while letting the older persons to death. The peaked disparity between supply and demand for healthcare properties raised a normative query of equitable resource allocation during the COVID-19 pandemic (Emanuel et al. 2020). Thousands of healthcare workers have already been infected worldwide (Gan et al. 2020), and the administrative and managerial departments are likely to place increased burdens and stresses on the frontline healthcare workers (Willan et al. 2020). Bangladesh has no exceptional scenario.

On 31 May 2020, GoB lifted its partial lockdown after 65 days of general holidays. The GoB claimed the withdrawal of lockdown as a test for next 15 days from 31 May to 15 June 2020, but it was decided without having the designated committees' opinion rather only considering the economic considerations. The GoB is planning to divide areas around the country that are affected by the COVID-19 into three zones based on colour as red, yellow, and green indicating the severity of cluster infections and to prevent the disease spread (The Daily Star 2020).

At present Bangladesh is at number 21 considering the infections and mortality from COVID-19 (Worldometer 2020). The overall attack rate among the Bangladeshi population is $208.9 / 1$ million and more than $20 \%$ positive cases have been identified in the recent days reported in the WHO situation report on 25th May 2020 (WHO 2020c). Among the countries of India, Pakistan, Nepal, Bhutan, Sri Lanka, Thailand and Vietnam, Bangladesh is at the bottom in terms of the number of COVID-19 tests done per million population (Newage 2020). The Maldives and Bhutan are on the top of the list with each conducting 


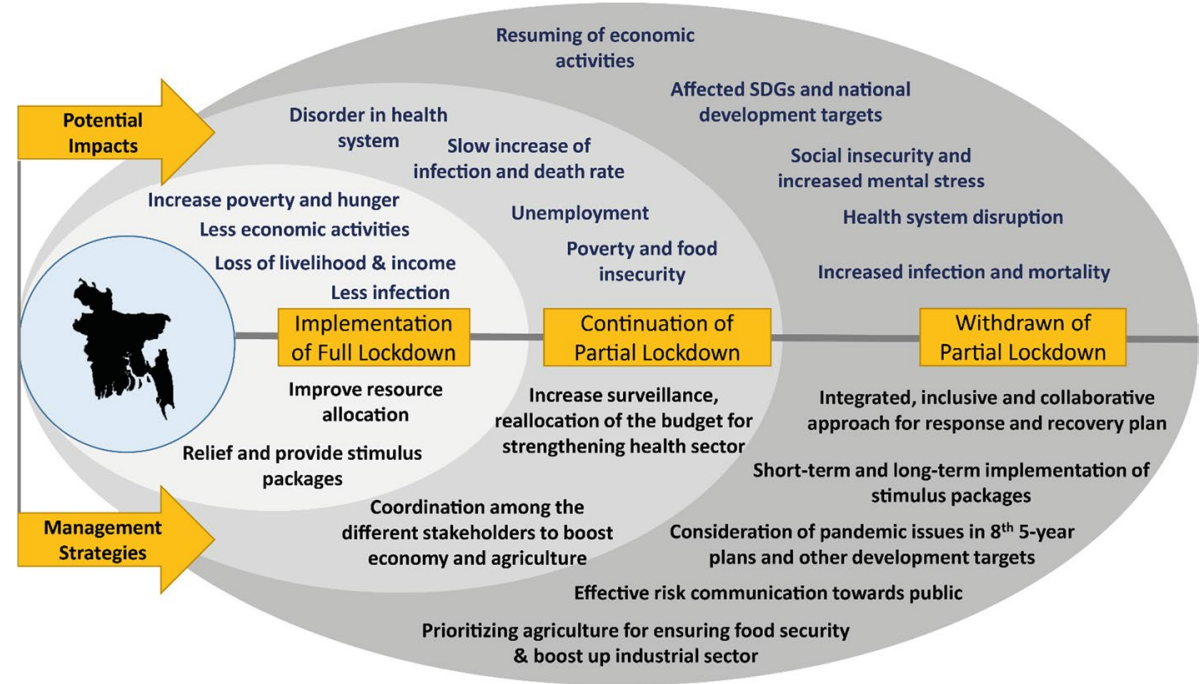

Fig. 6 Comparative lockdown scenarios with impact and management analysis for Bangladesh due to COVID-19 pandemic

21,822 tests per millions of people (TBS News 2020c). The testing laboratories are situated in the urban metropolitan areas and often due to fear and social stigma the patients do not want to test. Moreover, the incidences of a false negative in one laboratory while positive in another laboratory had been reported in mass media. In addition, the mortality rate from COVID-19 infection remains a puzzle which just cannot be explained by the GDP of the country, strength of healthcare governance and availability of equipment like ICU or ventilators. The trend of screening and testing (1877/1 million population) and contact tracing the COVID-19 patients in Bangladesh is not quite enough to conclude that the curve is flattening, or the peak of the curve has reached. Thus, at this point, the database does not seems to be robust and it could be chaotic from the epidemiological point of view.

After the lockdown is withdrawn, it was speculated that the number of infections will increase as the life and livelihood needed to sustain. On 31st May 2020, Bangladesh recorded 40 deaths from COVID-19 and 2545 new infections (IEDCR 2020). At this stage, GoB should increase the ICU numbers and strengthen the healthcare departments by recruiting more doctors, nurses, and technicians. Rapid testing, screening and diagnosis should be increased which was the advice of WHO from the beginning. Along with isolation, clinical management, and infection prevention and risk communication should be continued to the public. The GoB should engage public and private hospital authorities for the treatment of COVID-19 infected patients and resume treatment of other critical-care patients who are being deprived of any treatment at present. Moreover, as the infection from dengue is also rising government should take special emphasis for dengue treatment and management also. In Fig. 6 we have outlined the overall impact and management analysis of the three scenarios: scenario 1, scenario 2, and the scenario after the withdrawn of partial lockdown.

Community health workers can support pandemic preparation earlier to the epidemics by increasing access to the healthcare services and the healthcare products within the communities. They can communicate disease risks and increase awareness in the 
respected area in cultural language whereas reducing the weights of the formal healthcare systems. Community healthcare workers can also contribute to pandemic preparedness by acting as community-level educators and mobilizers, contributing to surveillance systems, and filling health service gaps (Boyce and Katz 2019). It is critical to detect cluster surveillance of COVID-19 to better allocate resources and improve decision-making as the outbreaks continue to grow in different districts of Bangladesh to improve resource allocation, faster testing stations, stricter quarantines and city/block lockdowns as well as travel bans (Desjardins et al. 2020).

It is predictable that environmentally the decrease in air pollution reduces preventable communicable and non-communicable diseases such as COVID-19 (Dutheil et al. 2020). Likewise, Ma et al. (2020) mentioned that the warmer season and lockdown activities were the keys to reduce exposure to novel coronavirus on humans in China. Although the relationship between the infection rate and climatic variables is not confirmed in Bangladesh, as the partial lockdown failed and continued, the number of infections over the past days indicates that GoB should have ensured proper implementation of the lockdown scenario 2 with limited public movement in the hotspots, resulting in lower community transmission of the virus and a slower death rate, while continuing economic activity with strict guidelines.

GoB was looking forward to exiting from partial lockdown beginning of May, yet no specific exit plans were executed by the government which should be scientifically rational and practically achieved. The exit plans from the lockdown should have been well communicated to the public ensuring transparency. Without ensuring safety and security the partial lockdown was withdrawn. Public transportation started on 31 May without maintaining any health guideline (TBS News 2020d). Coordination among the different stakeholders of the government is necessary, along with increased surveillance and resource allocation to the needy ones, to ensure supply of daily necessities, control price hikes, and reduce the loss of livelihood and unemployment. Moreover, very recently cyclone Amphan hit Bangladesh on 20 May 2020, living the coastal districts flooded and in the mayhem. Preliminary losses were estimated to be worth BDT12,744 crores (Dhaka Tribune 2020b). At this stage detection of COVID-19 hotspots by increased testing facilities all over the country must be ensured. The poor and vulnerable communities always lack food and nutrition due to injustice and corruption by local political stakeholders. The vulnerable groups, such as disabled and disadvantaged persons, young children and orphans, and elderly citizens, should be taken under protection for their well-being. They should be provided with food and nutrition for the time being.

COVID-19 pandemics cause environmental, economic, and social attributes which have only partially been described in Bangladesh. To fight this pandemic, it requires remarkable tasks and partnership development in the local and global level. The world must prepare for the likelihood that mitigation measures might fail because lockdown periods in different countries took different times to prevent or suspend the spread of COVID-19 (Gautam and Hens 2020). Collective responsibility is required from the public as well to protect themselves by abiding general health guideline, maintaining hygiene and social distancing, and avoiding going to crowded places and meetings. Extremely coordinated and effective planning and strategies for both the ongoing and afterwards response are required from the GoB to manage this pandemic and take it as a new "standard of normal". 


\section{Concluding remarks}

Considering the global hard-hit economy, depression, unemployment, job loss, shortfall of RMG export and incoming remittances, the socio-economic and development impacts along with the food insecurity as well as rising poverty due to COVID-19 at the community level need to be coordinated in Bangladesh. At present, as the lockdown is withdrawn, both lives and livelihoods are in danger which is a long-debate that is going on. Along with the pandemic disease, the upcoming seasons of natural disasters from cyclones, tidal floods, flash floods, and landslides of monsoon seasons should be considered to prepare for the emergencies. All these will further aggravate the humanitarian needs of the most vulnerable groups in the country in the coming months to be followed. As the health sector is the most strained at present, it will affect the targets of sustainable development goals of 2030. In addition, quality education will be hampered in the country. The government of Bangladesh has already mobilized a noteworthy stimulus package to support the affected industries and community which needs to be coordinated over a longer period of 12-18 months and may be incorporated in the upcoming 8th 5-year plans with substantial revising. However, this package should also include research and innovation, recovery of education. There is no alternative to strengthen the health care facilities and preparedness for the potential humanitarian crisis. Moreover, humanitarian support should reach the most vulnerable communities which need to be targeted, outlined, and delivered. Finally, economic implications should be subjected to the spatial and geographical locations based on the vulnerabilities. Hotspots identified in the delta plan can be considered here. The long-term strategic plan can be integrated into Perspective Plan 2041 and Bangladesh delta plans 2100, for better strategic management. Whatever will be the lockdown scenario, the basic supports to the mass people must be ensured and that is not so easy without strong strategic planning and multisectoral collaboration for sustainability including supports from the private sectors and international bodies.

Acknowledgements The authors would like to acknowledge all the frontline doctors, healthcare workers, emergency responders, security, and armed forces fighting this pandemic.

Funding This research did not receive any specific grant from funding agencies in the public, commercial, or not-for-profit sectors.

\section{Compliance with ethical standards}

Conflict of interest The authors declare no conflicts of interest.

Ethical statement Participants were informed of the specific purpose of the study. Participants' consent was taken before the survey and they remained anonymous. The survey was completed only once, and the survey could be completed/terminated whenever they wished. The survey content and procedure were reviewed and approved by the Department of Public Health and Informatics, Jahangirnagar University. 


\section{References}

Boyce, M. R., \& Katz, R. (2019). Community health workers and pandemic preparedness: Current and prospective roles. Frontiers of Public Health, 7, 62. https://doi.org/10.3389/fpubh.2019.00062.

BRAC. (2020). COVID-19 Situation report 9 April 2020. https://www.brac.net/covid19/res/sitrep/COVID -19-Sitrep_9-April-2020.pdf.

Business Insider. (2020). New Zealand has no new coronavirus cases and just discharged its last hospital patient. Here are the secrets to the country's success. Retrieved May 29, 2020, from https:// www.businessinsider.com/how-new-zealand-beat-coronavirus-testing-tracing-trust-in-government $-2020-5$.

Carinci, F. (2020). Covid-19: Preparedness, decentralisation, and the hunt for patient zero. BMJ. https://doi. org/10.1136/bmj.m799.

Chaudhury, D. R. (2018). At current pace, Bangladesh to end extreme poverty by 2021. The Economic Times. Retrieved November 6, 2018, from https://economictimes.indiatimes.com/news/international/ world-news/at-current-pace-bangladesh-to-end-extreme-poverty-by-2021/articleshow/66484544.cms.

Cousins, S. (2020). New Zealand eliminates COVID-19. The Lancet, 395(10235), 1474. https://doi. org/10.1016/s0140-6736(20)31097-7.

Desjardins, M. R., Hohl, A., \& Delmelle, E. M. (2020). Rapid surveillance of COVID-19 in the United States using a prospective space-time scan statistic: Detecting and evaluating emerging clusters. Applied Geography, 118, 102202. https://doi.org/10.1016/j.apgeog.2020.102202.

DeVellis, R. F. (1991). Scale development: Theory and applications. Newbury Park, CA: SAGE Publications.

Dhaka Tribune. (2020a). Coronavirus: BGMEA says orders worth $\$ 3.15$ billion cancelled so far. Retrieved April 20, 2020, from https://www.dhakatribune.com/bangladesh/2020/04/12/coronavirus-bgmea-repor ts-3-15-billion-in-order-cancellations.

Dhaka Tribune. (2020b). Cyclone Amphan: Bangladesh may face losses worth Tk12,744cr. Retrieved May 20, 2020, from https://www.dhakatribune.com/bangladesh/2020/05/20/cyclone-amphan-bangladesh -may-face-a-loss-of-tk12-744cr.

Djalante, R., Shaw, R., \& DeWit, A. (2020). Building resilience against biological hazards and pandemics: COVID-19 and its implications for the Sendai Framework. Progress in Disaster Science, 6, 100080. https://doi.org/10.1016/j.pdisas.2020.100080.

Dutheil, F., Baker, J. S., \& Navel, V. (2020). COVID-19 as a factor influencing air pollution? Environmental Pollution, 263(Pt A), 114466. https://doi.org/10.1016/j.envpol.2020.114466.

Emanuel, E., Persad, G., Upshur, R., Thome, B., Parker, M., Glickman, A., et al. (2020). Fair allocation of scarce medical resources in the time of Covid-19. New England Journal of Medicine. https://doi. org/10.1056/NEJMsb2005114.

FBCCI. (2020). Federation of Bangladesh chambers of Commerce \& Industries. http://fbcci.org/.

Galanakis, C. M. (2020). The food systems in the era of the coronavirus (COVID-19) pandemic crisis. Foods, 9(4), 523. https://doi.org/10.3390/foods9040523.

Gan, W. H., Lim, J. W., \& Koh, D. (2020). Preventing intra-hospital infection and transmission of coronavirus disease 2019 in health-care workers. Safety and Health at Work. https://doi.org/10.1016/j. shaw.2020.03.001.

Gautam, S., \& Hens, L. (2020). SARS-CoV-2 pandemic in India: What might we expect? Environment, Development and Sustainability, 22(5), 3867-3869. https://doi.org/10.1007/s10668-020-00739-5.

Gautam, S., \& Trivedi, U. (2020). Global implications of bio-aerosol in pandemic. Environment, Development and Sustainability, 22(5), 3861-3865. https://doi.org/10.1007/s10668-020-00704-2.

Gunnell, D., Appleby, L., Arensman, E., Hawton, K., John, A., Kapur, N., et al. (2020). Suicide risk and prevention during the COVID-19 pandemic. The Lancet Psychiattry. https://doi.org/10.1016/s2215 $-0366(20) 30171-1$.

Hussain, Z. (2020). What are the real choices? TBS News. Retrieved May 29, 2020, from https://tbsne ws.net/analysis/what-are-real-choices-86467?fbclid=IwAR2Kv361RfItY8fD52-7fKa66koGvH56NT x0baHr6AkaskZ1yDg2MVMYE7s.

IEDCR. (2020). Bangladesh COVID-19 update. Retrieved May 29, 2020, from https://www.iedcr.gov.bd/.

IEDCR/DGHS/GOB. (2020). National preparedness and response plan for COVID-19, Bangladesh. Dhaka.

Islam, A. R. M. T., Ahmed, N., Bodrud-Doza, M., \& Chu, R. (2017). Characterizing groundwater quality ranks for drinking purposes in Sylhet district, Bangladesh, using entropy method, spatial autocorrelation index, and geostatistics. Environmental Science \& Pollution Research, 24(34), 26350-26374. https ://doi.org/10.1007/s11356-017-0254-1.

Islam, A. R. M. T., Mamun, A. A., Zahid, A., \& Rahman, M. M. (2020). Simultaneous comparison of modified-integrated water quality and entropy weighted indices: Implication for safe drinking water in 
the coastal region of Bangladesh. Ecological Indicators, 113, 106229. https://doi.org/10.1016/j.ecoli nd.2020.106229.

Ji, Y., Ma, Z., Peppelenbosch, M. P., \& Pan, Q. (2020). Potential association between COVID-19 mortality and health-care resource availability. The Lancet Global Health., 8(4), e480. https://doi. org/10.1016/s2214-109x(20)30068-1.

Liu, C. W., Lin, K. H., \& Kuo, Y. M. (2003). Application of factor analysis in the assessment of groundwater quality in a Blackfoot disease area in Taiwan. Science of the Total Environment, 313(1-3), 77-89. https://doi.org/10.1016/S0048-9697(02)00683-6.

Liu, W., Yue, X. G., \& Tchounwou, P. B. (2020). Response to the COVID-19 epidemic: The Chinese experience and implications for other countries. International Journal of Environmental Research \& Public Health, 17(7), 1. https://doi.org/10.3390/ijerph17072304.

Luo, J. (2020). When will COVID-19 end? Data-driven prediction. Singapore University of Technology and Design. Retrieved from http://www.sutd.edu.sg. Accessed 25 May 2020.

Ma, Y., Zhao, Y., Liu, J., He, X., Wang, B., Fu, S., et al. (2020). Effects of temperature variation and humidity on the death of COVID-19 in Wuhan, China. Science of The Total Environment. https://doi. org/10.1016/j.scitotenv.2020.138226.

Mamun, M. A., \& Griffiths, M. D. (2020). First COVID-19 suicide case in Bangladesh due to fear of COVID-19 and xenophobia: Possible suicide prevention strategies. Asian Journal of Psychiatry, 51, 102073. https://doi.org/10.1016/j.ajp.2020.102073.

MinLaw/GoB. (2019). Penal code 1860: Section 144. Retrieved from http://bdlaws.minlaw.gov.bd/act11/section-2869.html. Accessed 25 May 2020.

Newage. (2020). Bangladesh worst coronavirus fighter in the region. Retrieved May 30, 2020, from http://www.newagebd.net/article/107228/bangladesh-worst-fighter-in-region?fbclid=IwAR1 vQmmICmArFBwsHiQQ1OBGVDNFzr33xxQqQsuXpbqorUV4OhQjBaweHeI.

Oppenheim, B., Gallivan, M., Madhav, N., Brown, N., Serhiyenko, V., Wolfe, N., et al. (2020). Assessing global preparedness for the next pandemic: Development and application of an Epidemic Preparedness Index. BMJ Global Health. https://doi.org/10.1136/bmjgh-2018-001157.

Roberton, T., Carter, E. D., Chou, V. B., Stegmuller, A. R., Jackson, B. D., Tam, Y., et al. (2020). Early estimates of the indirect effects of the COVID-19 pandemic on maternal and child mortality in lowincome and middle-income countries: A modelling study. The Lancet Global Health. https://www. thelancet.com/pdfs/journals/langlo/PIIS2214-109X(20)30229-1.pdf.

Shammi, M., \& Bodrud-Doza, M. (2020). Lockdown: To withdraw or not to withdraw? A scenariobased assessmen. TBS News 6 May 2020. Retrieved from https://tbsnews.net/thoughts/lockdownwithdraw-or-not-withdraw-77752?fbclid=IwAR0OanMRgoiRzOMt2afHrleXytyh49Utc0I8J9 YOcFjv0dBa-wApgS3mFjM. Accessed 25 May 2020.

Shammi, M., Bodrud-Doza, M., Islam, A. R. M. T., \& Rahman, M. M. (2020). COVID-19 pandemic, socioeconomic crisis and human stress in resource-limited settings: A case from Bangladesh. Heliyon, 6, e04063.

TBS News. (2020a). ICU space limited, critical Covid-19 patients at risk. Retrieved June 1, 2020, from https://tbsnews.net/coronavirus-chronicle/covid-19-bangladesh/icu-space-limited-critical-covid-19patients-risk-87277?fbclid=IwAR2Is3eJRafdYu8a9cENH5nsWnUKMHUb6Aq0Q5hkLduWPDQI hACnuoIuom4\#.XtSOe_rPeN0.facebook.

TBS News. (2020b). Half the country's Covid-19 infection in Dhaka city alone. Retrieved May 11, 2020, from https://tbsnews.net/coronavirus-chronicle/covid-19-bangladesh/bangladesh-reports-highestdaily-spike-1034-covid-19-cases.

TBS News. (2020c). Bangladesh lowest in Covid-19 testing in South Asia. Retrieved May 28, 2020, from https://tbsnews.net/coronavirus-chronicle/covid-19-bangladesh/bangladesh-lowest-covid-19testing-south-asia-86248.

TBS News. (2020d). Social distancing in public transport yet another cruel joke. Retrieved June 1, 2020, from https://tbsnews.net/thoughts/social-distancing-public-transports-yet-another-cruel-joke-87106 ?fbclid=IwAR0n8gkoStZnIuylFpQyBG7jYN93S5XOz9G9xESwzd6uS5hA7pNJhklCM7s\#.XtOeD 8nq9bs.facebook.

The Daily Star. (2020). Covid-19 pandemic: Govt plans to divide country into red, yellow, green zones. Retrieved June 1, 2020, from https://www.thedailystar.net/coronavirus-covid-19-pandemic-govtplans-divide-country-red-yellow-green-zones-1907405.

The Financial Express. (2020a). Economic ramifications of Covid-19 in Bangladesh. Retrieved May 6, 2020, from https://thefinancialexpress.com.bd/views/economic-ramifications-of-covid-19-in-bangl adesh-1588779315. 
The Financial Express. (2020b). COVID 19: SANEM proposes 2-year recovery plan for Bangladesh. Retrieved April 5, 2020, from https://thefinancialexpress.com.bd/economy/bangladesh/covid-19sanem-proposes-2-year-recovery-plan-for-bangladesh-1586070274.

Tian, H., Liu, Y., Li, Y., Wu, C., Chen, B., Kraemer, M., et al. (2020). An investigation of transmission control measures during the first 50 days of the COVID-19 epidemic in China. Science. https://doi. org/10.1126/science.abb6105.

Truog, R., Christine Mitchell, R., \& Daley, G. (2020). The toughest triage-Allocating ventilators in a pandemic. New England Journal of Medicine. https://doi.org/10.1056/NEJMp2005689.

UNDP. (2020a). UNDP Bangladesh situation analysis: Support to the National Response to contain the impact of COVID-19. Retrieved from May 31, 2020 https://www.bd.undp.org/content/bangladesh/en/ home/coronavirus/support-to-national-response.html.

UNDP. (2020b). COVID-19: Looming crisis in developing countries threatens to devastate economies and ramp up inequality. Retrieved from https://www.undp.org/content/undp/en/home/news-centr e/news/2020/COVID19_Crisis_in_developing_countries_threatens_devastate_economies.html. Accessed 25 May 2020.

Wang, Z., \& Tang, K. (2020). Combating COVID-19: Health equity matters. Nature Medicine. https://doi. org/10.1038/s41591-020-0823-6.

Wang, J., \& Wang, Z. (2020). Strengths, weaknesses, opportunities and threats (SWOT) analysis of China's prevention and control strategy for the COVID-19 epidemic. International Journal of Environmental Research \& Public Health, 17, 2235. https://doi.org/10.3390/ijerph17072235.

WEF. (2020a). Viet Nam shows how you can contain COVID-19 with limited resources. Retrieved from https://www.weforum.org/agenda/2020/03/vietnam-contain-covid-19-limited-resources/. Accessed 25 May 2020.

WEF. (2020b). Why we cannot lose sight of the sustainable development goals during coronavirus. Retrieved from https://www.weforum.org/agenda/2020/04/coronavirus-pandemic-effect-sdg-un-progr ess/. Accessed 25 May 2020.

WEF. (2020c). Coronavirus could trigger a hunger pandemic-Unless urgent action is taken. Retrieved from https://www.weforum.org/agenda/2020/04/covid-19-coronavirus-could-double-acute-hunger-un-warns ?fbclid=IwAR16jLHKFIovefpYF0jWCDVqQovvj3QsAxWx2TgQv-iWNMycRi9dydidr4o. Accessed 25 May 2020.

WHO. (2019). Health emergency and disaster risk management framework. Retrieved April 4, 2020, from https://www.who.int/hac/techguidance/preparedness/health-emergency-and-disaster-risk-management -framework-eng.pdf?ua $=1$.

WHO. (2020a). WHO coronavirus disease (COVID-19) dashboard. Retrieved May 28, 2020, from https:// covid19.who.int/?gclid=Cj0KCQjwwr32BRD4ARIsAAJNf_2nw_LfrI55KXi0rXbakV5OmQGfmT5 yP_XwrFD2R2nbMif8Z5jOx3UaAiEzEALw_wcB.

WHO. (2020b).WHO Bangladesh COVID-19 situation report no 10, 4 May 2020. Retrieved May 4, 2020, from https://www.who.int/docs/default-source/searo/bangladesh/covid-19-who-bangladesh-situationreports/who-ban-covid-19-sitrep-10.pdf?sfvrsn=c0aac0b8_4.

WHO. (2020c). WHO Bangladesh COVID-19 situation report no 13, 25 May 2020. Retrieved May 25, 2020, from https:/www.who.int/docs/default-source/searo/bangladesh/covid-19-who-bangladesh-situa tion-reports/who-ban-covid-19-sitrep-13-20200525.pdf?sfvrsn=a15591c0_4.

Willan, J., King, A. J., Jeffery, K., \& Bienz, N. (2020). Challenges for NHS hospitals during covid-19 epidemic. BMJ, 368, m1117. https://doi.org/10.1136/bmj.m1117.

World Bank. (2020). Bangladesh must ramp up COVID-19 action to protect its people, revive economy. Retrieved from https://www.worldbank.org/en/news/press-release/2020/04/12/bangladesh-must-actnow-to-lessen-covid-19-health-impacts. Accessed 25 May 2020.

Worldometer. (2020). COVID-19 coronavirus pandemic. Retrieved May 31, 2020, from https://www.world ometers.info/coronavirus/?utm_campaign=homeAdvegas 1 ?.

Wright, N., Fagan, L., Lapitan, J. M., Kayano, R., Abrahams, J., Huda, Q., et al. (2020). Health emergency and disaster risk management: Five years into implementation of the Sendai framework. International Journal of Disaster Risk Science, 11(2), 206-217. https://doi.org/10.1007/s13753-020-00274-X.

Zhang, S., Wang, Z., Chang, R., Wang, H., Xu, C., Yu, X., et al. (2020). COVID-19 containment: China provides important lessons for global response. Frontiers of Medicine. https://doi.org/10.1007/s1168 4-020-0766-9.

Publisher's Note Springer Nature remains neutral with regard to jurisdictional claims in published maps and institutional affiliations. 


\section{Affiliations}

Mashura Shammi ${ }^{1}$. Md. Bodrud-Doza ${ }^{2} \cdot$ Abu Reza Md. Towfiqul Islam ${ }^{3}$. Md. Mostafizur Rahman ${ }^{1}$

Mashura Shammi

mashura926@juniv.edu

$\bowtie$ Md. Mostafizur Rahman rahmanmm@juniv.edu

Md. Bodrud-Doza

bodrud.d@brac.net

Abu Reza Md. Towfiqul Islam towfiq_dm@brur.ac.bd

1 Department of Environmental Sciences, Jahangirnagar University, Dhaka 1342, Bangladesh

2 Climate Change Programme, BRAC, Dhaka 1212, Bangladesh

3 Department of Disaster Management, Begum Rokeya University, Rangpur 5400, Bangladesh 